\title{
Endoscopy in patients on antiplatelet or anticoagulant therapy: British Society of Gastroenterology (BSG) and European Society of Gastrointestinal Endoscopy (ESGE) guideline update
}

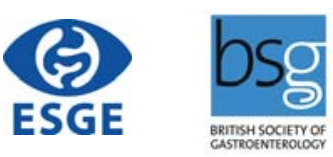

(i) $(2)$

Authors

Andrew M. Veitch ${ }^{1}$, Franco Radaelli², Raza Alikhan ${ }^{3}$, Jean-Marc Dumonceau ${ }^{4} \oplus$, Diane Eaton ${ }^{5}$, Jo Jerrome ${ }^{6}$, Will Lester $^{7}$, David Nylander ${ }^{8}$, Mo Thoufeeq ${ }^{9}$, Geoffroy Vanbiervliet ${ }^{10}$, James R. Wilkinson ${ }^{11}$, Jeanin E. van Hooft ${ }^{12}$

Institutions

1 Department of Gastroenterology, Royal Wolverhampton NHS Trust, Wolverhampton, United Kingdom

2 Gastroenterology Department, Valduce Hospital, Como, Italy

3 Department of Haematology Cardiff and Vale University Health Board, Cardiff, United Kingdom

4 Department of Gastroenterology, Charleroi University Hospitals, Charleroi, Belgium

5 Anticoagulation UK, London, United Kingdom

6 Thrombosis UK, Llanwrda, United Kingdom

7 Department of Haematology University Hospitals Birmingham NHS Foundation Trust, Birmingham,

8 Department of Gastroenterology, The Newcastleupon-Tyne NHS Foundation Trust, Newcastle-uponTyne

9 Department of Gastroenterology, Sheffield Teaching Hospitals NHS Foundation Trust, Sheffield

10 Pôle digestif, Hôpital Universitaire L’Archet 2, Nice, France

11 Department of Interventional Cardiology, University Hospital Southampton NHS Foundation Trust, Southampton, United Kingdom

12 Department of Gastroenterology and Hepatology, Leiden University Medical Centre, Leiden, Netherlands

published online 6.8 .2021

Bibliography

Endoscopy 2021; 53: 947-969

DOI 10.1055/a-1547-2282

ISSN 0013-726X

(c) 2021. European Society of Gastrointestinal Endoscopy, British Society of Gastroenterology, the Author(s) or their employer(s).
This is an open access article published by Thieme and BMJ Publishing Group Ltd under the terms of the Creative Commons Attribution Non Commercial License, permitting copying and reproduction so long as the original work is given appropriate credit. Contents may not be used for commercial purposes. (https://creativecommons.org/licenses/by-nc/4.0/)

Georg Thieme Verlag KG, Rüdigerstraße 14, 70469 Stuttgart, Germany

( Supplementary material

Supplementary material is available under

https://doi.org/10.1055/a-1547-2282

Corresponding author

Andrew M. Veitch, Royal Wolverhampton NHS Trust, New Cross Hospital, Wolverhampton, WV10 0QP, United Kingdom andrew.veitch@nhs.net

\section{ABSTRACT}

This is a collaboration between the British Society of Gastroenterology (BSG) and the European Society of Gastrointestinal Endoscopy (ESGE), and is a scheduled update of their 2016 guideline on endoscopy in patients on antiplatelet or anticoagulant therapy. The guideline development committee included representatives from the British Society of Haematology, the British Cardiovascular Intervention Society, and two patient representatives from the charities Anticoagulation UK and Thrombosis UK, as well as gastroenterologists. The process conformed to AGREE II principles, and the quality of evidence and strength of recommendations were derived using GRADE methodology. Prior to submission for publication, consultation was made with all member societies of ESGE, including BSG. Evidencebased revisions have been made to the risk categories for endoscopic procedures, and to the categories for risks of thrombosis. In particular a more detailed risk analysis for atrial fibrillation has been employed, and the recommendations for direct oral anticoagulants have been strengthened in light of trial data published since the previous version. A 
section has been added on the management of patients presenting with acute Gl haemorrhage. Important patient considerations are highlighted. Recommendations are based on the risk balance between thrombosis and haemor-

rhage in given situations.

\section{PUBLICATION INFORMATION}

This article is published simultaneously in the journals Endoscopy and Gut. (C) 2021. European Society of Gastrointestinal Endoscopy, British Society of Gastroenterology, the Author(s) or their employer(s). This article is published by Thieme.

\section{Summary of recommendations}

Recommendations for the management of patients on antiplatelet therapy or anticoagulants undergoing elective endoscopic procedures are summarised in $>$ Figs. 1 and $\$ 2$. Risk stra- tification for endoscopic procedures are detailed in $>$ Table $\mathbf{1}$, for antiplatelet agents in $\mathbf{r}$ Table 2 , and for heparin bridging in patients on warfarin $>$ Table 3 .

We recommend that all patients are advised of the thrombotic risks of discontinuing antiplatelets or anticoagulants, as well as the haemorrhagic risks of continuing therapy (strong recommendation, low quality evidence)

For all endoscopic procedures we recommend continuing aspirin (strong recommendation, low quality evidence), with the exception of ampullectomy (weak recommendation, low quality evidence). If considering aspirin discontinuation, this should be on an individual patient basis depending on the risks of thrombosis vs haemorrhage (weak recommendation, low quality evidence).

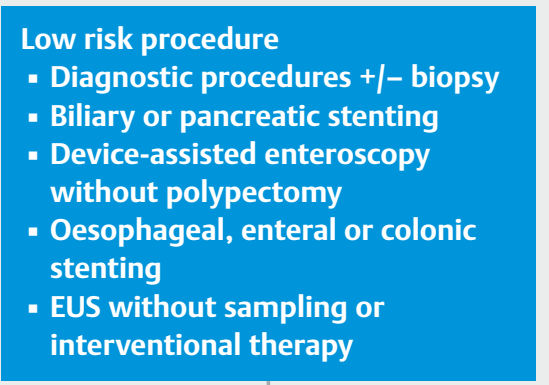

- Clopidogrel
- Prasugrel
- Ticagrelor
Continue therapy

- Fig. 1 Guidelines for the management of patients on P2Y12 receptor antagonist antiplatelet agents undergoing endoscopic procedures: 2021 update.

(EUS: endoscopic ultrasound, ERCP: endoscopic retrograde cholangiopancreatography, EMR: endoscopic mucosal resection, ESD: endoscopic submucosal dissection, PEG: percutaneous endoscopic gastroenterostomy)

High risk procedure

- Polypectomy (consider cold snare colonic polypectomy $<1 \mathrm{~cm}$ on continued clopidogrel monotherapy)

- ERCP with sphincterotomy

- EMR/ESD

- Dilatation of strictures

- Therapy of varices

- PEG

- EUS-guided sampling or with interventional therapy

- Oesophageal or gastric radiofrequency ablation

- Clopidogrel

- Prasugrel

- Ticagrelor
Low risk condition

- Ischaemic heart disease without coronary stent

- Cerebrovascular disease

- Peripheral vascular disease

Stop clopidogrel, prasugrel or ticagrelor 7 days before endoscopy

- Continue aspirin if already prescribed

- Restart clopidogrel, prasugrel or ticagrelor 1 - 2 days after procedure $\downarrow$

High risk condition

- Coronary artery stents

Discuss strategy with consultant interventional cardiologist

- Consider temporary cessation of P2Y12 receptor antagonist if: 6 - 12 months after insertion of drugeluting coronary stent $>1$ month after insertion of bare metal coronary stent

- Continue aspirin 
Low risk procedure

- Diagnostic procedures +/- biopsy

- Biliary or pancreatic stenting

- Device-assisted enteroscopy without polypectomy

- Oesophageal, enteral or colonic stenting

- EUS without sampling or interventional therapy

\begin{tabular}{|l|l|}
\hline \multicolumn{1}{|c|}{$\downarrow$} & \\
\hline Warfarin & $\begin{array}{l}\text { DOAC } \\
\text { - Dabigatran } \\
\text { - Rivaroxaban }\end{array}$ \\
\hline $\begin{array}{l}\text { Continue Warfarin } \\
\text { Check INR } 1 \text { week } \\
\text { before endoscopy } \\
\text { - If INR wihin } \\
\text { therapeutic range } \\
\text { continue usual } \\
\text { daily dose }\end{array}$ & $\begin{array}{l}\text { - Edoxaban } \\
\text { - If INR above }\end{array}$ \\
\hline
\end{tabular}

therapeutic range

but $<5$ reduce

daily dose until INR

returns to

therapeutic range
High risk procedure

- Polypectomy

- ERCP with sphincterotomy

- EMR/ESD

- Dilatation of strictures

- Therapy of varices

- PEG

- EUS-guided sampling or with interventional therapy

- Oesophageal or gastric radiofrequency ablation

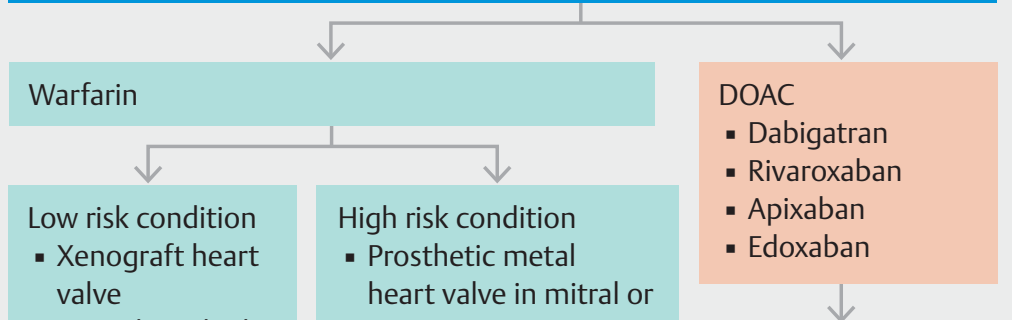

- AF without high risk factors

$\left(\mathrm{CHADS}_{2} \leq 4\right)$

- > 3 months after VTE

aortic position

- Prosthetic heart valve and $\mathrm{AF}$

- $A F$ and mitral stenosis

- AF with previous stroke/TIA and 3 or more of:

- Congestive cardiac failure

- Hypertension*

- Age > 75 years

- Diabetes mellitus

- AF and stroke/TIA within 3 months

- <3 months after VTE

- Previous VTE on anticoagulation**

- Check INR 1 week later to ensure adequate anticoagulation
Take last dose of drug 3 days before endoscopy

- For dabigatran with $\mathrm{CrCl}$ (eGFR) 30 - $50 \mathrm{ml} / \mathrm{min}$ take last dose 5 procedure. In any patient with rapidly deteriorating renal function a haematologist should be consulted

- Restart DOAC 2 - 3 days after procedure*** days before the

\section{Sto}

Stop warfarin for 5 days

before endoscopy

- Start LMWH 2 days after stopping warfarin

- Omit LMWH on day of procedure

- Restart warfarin evening of procedure with usually dose

- Continue LMWH until INR adequate

- Fig. 2 Guidelines for the management of patients on anticoagulants undergoing endoscopic procedures: 2021 update.

*Blood pressure $>140 / 90 \mathrm{mmHg}$ or on antihypertensive medication

** Previous VTE on anticoagulation and target INR now 3.5

*** depends on haemorrhagic and thrombotic risk, consider extending interval for ESD

(EUS: endoscopic ultrasound, ERCP: endoscopic retrograde cholangiopancreatography, EMR: endoscopic mucosal resection, ESD: endoscopic submucosal dissection, PEG: percutaneous endoscopic gastroenterostomy, INR: international normalised ratio, AF: atrial fibrillation, VTE: venous thromboembolism, TIA: transient ischaemic attack, LMWH: low molecular weight heparin) 
- Table 1 Risk stratification of endoscopic procedures based on the risks of haemorrhage and of intervention required to treat a complication.

\begin{tabular}{|l|l|}
\hline High risk procedures & Low risk procedures \\
\hline Endoscopic polypectomy* & $\begin{array}{l}\text { Diagnostic procedures } \pm \text { biopsy } \\
\text { sampling }\end{array}$ \\
\hline ERCP with sphincterotomy & Biliary or pancreatic stenting \\
\hline Ampullectomy & $\begin{array}{l}\text { Device-assisted enteroscopy } \\
\text { without polypectomy }\end{array}$ \\
\hline $\begin{array}{l}\text { Endoscopic mucosal resection } \\
\text { or endoscopic submucosal dis- } \\
\text { section }\end{array}$ & $\begin{array}{l}\text { Oesophageal, enteral or colonic } \\
\text { stenting }\end{array}$ \\
\hline $\begin{array}{l}\text { Endoscopic dilatation of stric- } \\
\text { tures in the upper or lower } \\
\text { gastrointestinal tract }\end{array}$ & $\begin{array}{l}\text { Endoscopic ultrasound without } \\
\text { sampling or interventional ther- } \\
\text { apy }\end{array}$ \\
\hline $\begin{array}{l}\text { Endoscopic therapy of varices } \\
\text { Percutaneous endoscopic } \\
\text { gastrostomy }\end{array}$ & \\
\hline $\begin{array}{l}\text { Endoscopic ultrasound-guided } \\
\text { sampling or with interventional } \\
\text { therapy }\end{array}$ & \\
\hline $\begin{array}{l}\text { Oesophageal or gastric radio- } \\
\text { frequency ablation }\end{array}$ & \\
\hline $\begin{array}{l}\text { ERCP, endoscopic retrograde cholngiopancreatography } \\
\text { consider cold snare resection of polyps }<1 \mathrm{~cm} \text { on continued clopidogrel } \\
\text { monotherapy }\end{array}$ & \\
\hline
\end{tabular}

- Table 2 Risk stratification for discontinuation of P2Y12 receptor antagonists clopidogrel, prasugrel or ticagrelor based on the risk of thrombosis.

\begin{tabular}{|l|l|}
\hline High risk of thrombosis & Low risk of thrombosis \\
\hline $\begin{array}{l}\text { Drug eluting coronary artery stents } \\
\text { within } 12 \text { months of placement }\end{array}$ & $\begin{array}{l}\text { Ischaemic heart disease } \\
\text { without coronary stents }\end{array}$ \\
\hline $\begin{array}{l}\text { Bare metal coronary artery stents } \\
\text { within } 1 \text { month of placement }\end{array}$ & Cerebrovascular disease \\
\hline
\end{tabular}

Peripheral vascular disease

\section{Low-risk endoscopic procedures}

For low-risk endoscopic procedures we recommend continuing P2Y12 receptor antagonists as single or dual antiplatelet therapy (strong recommendation, low quality evidence).

For low-risk endoscopic procedures we suggest that warfarin therapy should be continued (weak recommendation, low quality evidence). It should be ensured that the INR does not exceed the therapeutic range in the week prior to the procedure (strong recommendation, low quality evidence).

For low-risk endoscopic procedures we suggest omitting the morning dose of DOACs on the day of the procedure (weak recommendation, low quality evidence).

- Table 3 Risk stratification for discontinuation of warfarin therapy with respect to the requirement for heparin bridging

\begin{tabular}{|l|l|}
\hline High risk of thromboembolism & $\begin{array}{l}\text { Low risk of throm- } \\
\text { boembolism }\end{array}$ \\
\hline $\begin{array}{l}\text { Prosthetic metal heart valve in mitral or } \\
\text { aortic }{ }^{1} \text { position }\end{array}$ & Xenograft heart valve \\
\hline Prosthetic heart valve and atrial fibrillation & \\
\hline Atrial fibrillation and mitral stenosis & \\
\hline $\begin{array}{l}\text { Atrial fibrillation with previous stroke or } \\
\text { transient ischemic attack+3 or more of: }\end{array}$ & $\begin{array}{l}\text { Atrial fibrillation } \\
\text { without high-risk } \\
\text { factors } \\
\text { - Congestive cardiac failure }\end{array}$ \\
\hline $\begin{array}{l}\text { - Hypertension } \\
\text { - Age }>75 \text { years }\end{array}$ & \\
\hline - Diabetes mellitus & \\
\hline
\end{tabular}

Atrial fibrillation and previous stroke or transient ischaemic attack within 3 months

$<3$ months after venous thromboembolism $^{3}$

$>3$ months after venous thromboembolism

Previous venous thromboembolism on warfarin, and target INR now 3.5

Thrombophilia syndromes do not usually require heparin bridging, but individual cases should be discussed with a haematologist

${ }^{1}$ heparin bridging for a metal aortic valve is recommended by European Society of Cardiology (ESC) and the European Association for Cardio-Thor acic Surgery (EACTS) guidelines 2017 [33], but this varies between international guidelines [31,32] and local guidance should be established in conjunction with cardiology or cardiothoracic services.

2 Blood pressure $>140 / 90 \mathrm{mmHg}$ or on antihypertensive medication

${ }^{3}$ the majority of patients are now on DOACs for venous thromboembolism and bridging is not appropriate. Consider deferring a high risk procedure beyond 3 months therapy in this high risk group for thromboembolism

\section{High-risk endoscopic procedures}

For high-risk endoscopic procedures in patients at low thrombotic risk, we recommend discontinuing P2Y12 receptor antagonists 7 days before the procedure (strong recommendation, moderate quality evidence). In patients on dual antiplatelet therapy, we recommend continuing aspirin (strong recommendation, low quality evidence).

For high-risk endoscopic procedures in patients at low thrombotic risk, we recommend discontinuing warfarin for 5 days before the procedure (strong recommendation, high quality evidence). Check INR prior to the procedure to ensure $<1.5$ (strong recommendation, low quality evidence).

For high-risk endoscopic procedures in patients at high thrombotic risk, we recommend continuing aspirin and liaising with a consultant interventional cardiologist about the risk/ benefit of discontinuing P2Y12 receptor antagonists (strong recommendation, high quality evidence).

For high-risk endoscopic procedures in patients at high thrombotic risk, we recommend that warfarin should be temporarily discontinued and substituted with low molecular weight heparin (strong recommendation, low quality evidence). 
For high-risk endoscopic procedures in patients on DOACs, we recommend that the last dose of DOACs be taken 3 days before the procedure (strong recommendation, low quality evidence). For patients on dabigatran with a $\mathrm{CrCl}$ (or eGFR) of 30$50 \mathrm{~mL} / \mathrm{min}$ we recommend that the last dose be taken 5 days prior to the procedure (strong recommendation, low quality evidence). In any patient with rapidly deteriorating renal function a haematologist should be consulted (strong recommendation, low quality evidence).

\section{Post elective endoscopic procedures}

If antiplatelet or anticoagulant therapy is discontinued, then we recommend this should be resumed up to 2 to 3 days after the procedure depending on the perceived haemorrhagic and thrombotic risks (strong recommendation, moderate quality evidence).

For all patients on antiplatelets or anticoagulants we recommend advising that there is an increased risk of post-procedure haemorrhage compared to patients not on these drugs (strong recommendation, low quality evidence).

\section{Acute GI haemorrhage}

We suggest that permanent discontinuation of aspirin for primary prophylaxis should be considered (weak recommendation, low quality evidence).

We suggest that aspirin for secondary prevention should not be routinely stopped. If it is stopped, it should be recommenced as soon as haemostasis is achieved, or there is no further evidence of haemorrhage (strong recommendation, moderate quality evidence).

We recommend that dual antiplatelet therapy is continued if possible in patients with coronary stents in situ and management should be in liaison with a consultant interventional cardiologist (strong recommendation, moderate quality evidence). In the case of major haemorrhage we recommend continuing aspirin if the $\mathrm{P} 2 \mathrm{Y} 12$ receptor antagonist is interrupted (strong recommendation, moderate quality evidence). P2Y12 receptor antagonist therapy should be re-instated within 5 days, if still indicated (strong recommendation, moderate quality evidence).

We recommend withholding oral anticoagulant and correcting coagulopathy according to the severity of haemorrhage and the patient's thrombotic risk in coordination with a consultant cardiologist/ haematologist. The correction of coagulopathy should not delay endoscopy or radiologic intervention (strong recommendation, low quality evidence).

In patients with haemodynamic instability who take vitamin $\mathrm{K}$ antagonists (VKAs), we recommend administering intravenous vitamin $\mathrm{K}$ and four-factor prothrombin complex concentrate (PCC) (strong recommendation, low quality evidence), or fresh frozen plasma if PCC is not available (weak recommendation, very low quality evidence)

In patients with haemodynamic instability who take DOACs, we suggest considering the use of reversal agents: idarucizumab in dabigatran treated patients, and andexanet in antifactor Xa treated patients (weak recommendation, low quality evidence), or intravenous four-factor PCC if andexanet is not available (weak recommendation, very low quality evidence)

We recommend restarting anticoagulation following acute GI haemorrhage in patients with an indication for long-term anticoagulation (strong recommendation, low quality evidence). In patients at low thrombotic risk, we suggest restarting anticoagulation as soon as possible after seven days of anticoagulant interruption (weak recommendation, low quality evidence). In those at high-thrombotic risk, an earlier resumption of anticoagulation with heparin bridging, preferably within 3 days, is recommended (strong recommendation, low quality evidence).

\section{Introduction and methods}

The British Society of Gastroenterology (BSG) and the European Society of GI Endoscopy (ESGE) jointly published guidelines on endoscopy in patients on antiplatelet or anticoagulant therapy, including direct oral anticoagulants in 2016 [1,2]. This is a scheduled five year update on the previous guidelines.

These guidelines were drafted by a working party comprising members of the BSG and ESGE, two haematologists representing the Thrombosis and Haemostasis Task Force of the British Society of Haematology, an interventional cardiologist representing the British Cardiovascular Intervention Society, and two patient representatives from the charities Anticoagulation UK and Thrombosis UK. Guidelines were prepared according to AGREE II principles [3] and comply with the requirements of the National Institute for Health and Care Excellence (NICE). Clinical questions were formulated using the PICO (Patients, Interventions, Controls, Outcomes) system. Search strategies were delegated to authors with responsibilities for specific sections. Literature searches were conducted using PubMed and OVID Medline, Embase and Cochrane Library. Additional searches were conducted using Google. Literature searches were run up to November 2020, and this time-point should be the starting point in the search for new evidence for future updates to these Guidelines. Quality of evidence and strength of recommendations were determined by the authors, and consensus achieved according to the GRADE system [4]. After agreement on a final version, the manuscript was subjected to internal peer review and revision by the BSG and the ESGE and sent to all individual ESGE members and member societies prior to publication. Conflict of interest statements were submitted by all authors and are listed at the end of this manuscript. This guideline was issued in 2021 and will be considered for review in 2026, or sooner if new evidence becomes available. This guideline has been co-published with permission in both Gut and Endoscopy.

\section{Patient considerations}

We recommend that all patients are advised of the thrombotic risks of discontinuing antiplatelets or anticoagulants, as well as the haemorrhagic risks of continuing therapy (strong recommendation, low quality evidence). 


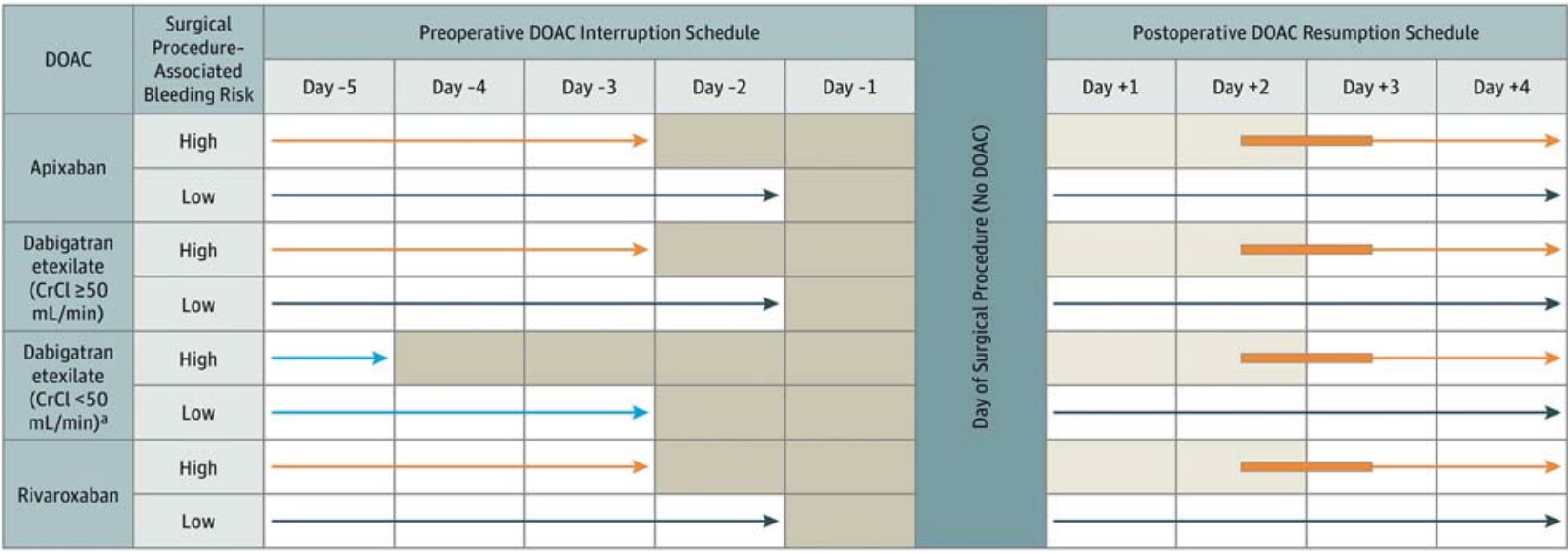

- Fig.3 Perioperative direct oral anticoagulant (DOAC) management protocol. Reproduced with permission from JAMA Intern Med 2019:179 (11);1469-78. Copyright (2019) American Medical Association. All rights reserved. [rerif]

No DOAC was taken on certain days (shaded) and on the day of the elective surgery or procedure (including endoscopy). The light blue arrows refer to an exception to the basic management, a subgroup of patients taking dabigatran with a creatinine clearance $(\mathrm{CrCl}) \mathrm{less}$ than $50 \mathrm{ng} / \mathrm{ml}$. The orange arrows refer to patients having a high-bleed-risk procedure. Dark blue arrows refer to patients having a low-bleed-risk procedure. The thickened orange arrows refer to flexibility in timing of DOAC resumption after a procedure.

For all patients on antiplatelets or anticoagulants we recommend advising that there is an increased risk of post-procedure haemorrhage compared to patients not on these drugs (strong recommendation, low quality evidence).

As discussed, management of antithrombotic drugs is a balance of the risks of haemorrhage from the procedure versus the risks of thrombosis if antithrombotic medication is discontinued or modified. Haemorrhage secondary to high-risk endoscopic procedures can often be controlled by further endoscopic therapeutic measures, and is rarely fatal. A thrombotic stroke may result in lifelong disability, and a major cardiac event may result in death. Not only do the risks of thrombosis vs haemorrhage need to be assessed on an individual patient basis, but patients should be fully informed, and involved in this decision-making process. The risk of a potentially catastrophic thrombotic event such as a stroke may not be acceptable to a patient even if that risk is very low.

Once the decision to modify antithrombotic medication is made, then a personal plan for that patient should be made. This should include written as well as verbal information regarding the precise timing of any changes. This should include the time of last dose of a drug, and first dose when restarting. If multiple drugs are involved, or substitutions including bridging with heparin, then timing respective to each drug should be clearly communicated. Simple algorithms such as those illustrated in the PAUSE trial for DOACs [5] may be useful ( $>$ Fig.3). Late haemorrhagic complications may occur one to two weeks after endoscopic therapy, and antithrombotic therapy will have often been reinstituted prior to this. Patients on antithrombotics should be advised that there is a possible increase in post procedure haemorrhage, and also advised how to seek urgent medical advice at any time of the day or night. We have pro- duced a patient information sheet based on this guideline to assist with patient engagement (online supplemental file).

\section{Antiplatelet agents}

For all endoscopic procedures we recommend continuing aspirin (strong recommendation, low quality evidence), with the exception of ampullectomy (weak recommendation, low quality evidence). If considering aspirin discontinuation, this should be on an individual patient basis depending on the risks of thrombosis vs haemorrhage (weak recommendation, low quality evidence).

For low-risk endoscopic procedures we recommend continuing P2Y12 receptor antagonists as single or dual antiplatelet therapy (strong recommendation, low quality evidence).

For high-risk endoscopic procedures in patients at low thrombotic risk, we recommend discontinuing P2Y12 receptor antagonists 7 days before the procedure (strong recommendation, moderate quality evidence). In patients on dual antiplatelet therapy, we recommend continuing aspirin (strong recommendation, low quality evidence).

For high-risk endoscopic procedures in patients at high thrombotic risk, we recommend continuing aspirin and liaising with a consultant interventional cardiologist about the risk/ benefit of discontinuing P2Y12 receptor antagonists (strong recommendation, high quality evidence).

\section{Aspirin}

When given as long-term secondary prevention aspirin reduces vascular events by approximately one-third and vascular deaths by about one-sixth. In patients on long-term low-dose aspirin for secondary prevention, aspirin interruption was associated with a three-fold increased risk of cardiovascular or cerebrovas- 
cular events, and $70 \%$ of these events occurred within 7-10 days after interruption [6,7]. In a randomized controlled trial (RCT) of 220 patients on low-dose aspirin for secondary prevention undergoing non-cardiac surgery, patients were randomized to continuation or temporary replacement of aspirin by placebo.[8] Major cardiac events occurred within 30 days in $1.8 \%$ of the aspirin group compared to $9 \%$ in the placebo group $(p=0.02)$. No difference in haemorrhagic complications was seen between the two groups. The risks related to continuation or discontinuation of aspirin for endoscopy are discussed in the sections on endoscopic procedures, and recommendations made accordingly.

With regard to patients on a DOAC and a single antiplatelet agent, such as aspirin, the AFIRE trial randomized patients with atrial fibrillation and stable coronary artery disease to rivaroxaban alone versus rivaroxaban and a single antiplatelet. They demonstrated that rivaroxaban alone was non inferior for the primary efficacy endpoint (a composite of thromboembolic events or death from any cause) and superior for the primary safety endpoint of major bleeding. However, this trial was not sufficiently powered to address the risk of stent thrombosis [9]. For patients with documented coronary artery disease and an indication for formal anticoagulation, e. g. atrial fibrillation, then a life-long single antiplatelet such as aspirin is no longer recommended, beyond the antiplatelet duration required post coronary stent insertion, in the latest ESC guidelines [10]. However, late stent thrombosis (1-12 months post stent implantation) and very late stent thrombosis (beyond 12 months post stent implantation) occur with a reported incidence of $0.5-$ $1.0 \%$ and $0.2-0.4 \%$ respectively, and stent thrombosis is associated with a with a $4-45 \%$ mortality [11]. Furthermore, technical aspects of the procedure, for example left main stents, may have an essential bearing on the subsequent risk of stent thrombosis. The trials addressing whether a long-term antiplatelet agent is needed in patients that have stents and require a DOAC, which suggest a DOAC alone may be safe, are not sufficiently powered to look at the important endpoint of stent thrombosis $[9,12]$. Many consultant interventional cardiologists in the UK recommend their patients remain on a single antiplatelet agent if they have stents and need a long term DOAC, although this will very much vary on an individual case-by-case basis. Therefore, in patients with coronary stents who are taking a DOAC the cessation of the single antiplatelet agent should always be discussed in advance with the consultant interventional cardiologist responsible for the patient's care.

Following the publication of three RCTs in 2018 the use of aspirin in primary prevention in cardiovascular disease is no longer routinely recommended and should only be considered, on a case-by-case basis, in those with a very high individual risk of cardiovascular events [13].

\section{P2Y12 receptor antagonists}

Antiplatelet drugs have a rapid onset of action, and irreversibly inhibit platelet activity. Clopidogrel, prasugrel and ticagrelor are antagonists of the P2Y12 receptor on platelets. Clopidogrel plus aspirin is more potent than aspirin alone [14]. For clopidogrel, platelet function returns to normal 5-7 days after withdra- wal of the drug [15]. Prasugrel and ticagrelor are more rapidly acting and more potent platelet receptor antagonists than clopidogrel. Clopidogrel monotherapy may be used following a thromboembolic cerebrovascular accident, or for peripheral vascular disease. P2Y12 receptor antagonists are frequently used as dual antiplatelet therapy (DAPT) with aspirin in acute coronary syndrome (ACS) and after placement of coronary stents. High- and low-risk indications for P2Y12 receptor antagonists are listed in $>$ Table 2.

Patients on DAPT, with aspirin and a P2Y12 receptor antagonist, particularly in the context of coronary artery stents, are at high risk of thrombosis if drug therapy is discontinued. Without antiplatelet therapy coronary stents are at high risk of occlusion due to thrombosis, and this confers an approximate $40 \%$ risk of acute myocardial infarction or death. In one study, discontinuation of DAPT was associated with a hazard ratio (HR) of 161 for these events [16]. DAPT is generally prescribed for 12 months after drug eluting stents (DES) implantation, though there have been occasional reported instances of thrombosis after this duration. Prasugrel and ticagrelor are now the main drugs of choice used for ACS in the UK. Prasugrel has been shown in a large UK observational series to be associated with a lower mortality [17] This has been confirmed in a large randomised openlabel trial [18]. The latest NICE guidelines for ACS now recommend prasugrel is used as the first line agent in ACS, unless the patient is on anticoagulant therapy, in which case clopidogrel is recommended. Clopidogrel is generally the first choice of P2Y12 inhibitor in patients undergoing elective percutaneous coronary intervention $(\mathrm{PCl})$ and the current guidelines recommend a six-month course of DAPT post elective PCI [10]. Where temporary cessation of $\mathrm{P} 2 \mathrm{Y} 12$ inhibitors in patients with stents has been agreed, after discussion with the responsible consultant interventional cardiologist, then stopping the P2Y12 inhibitors seven days pre-procedure will minimise the bleeding risk. However, it should be noted that, depending on the P2Y12 agent, this time can be shortened dependent on the P2Y12 agent in use. In patients with a very high risk of stent thrombosis there may also be a role for bridging either with i.v. cangrelor and/or Gllbllla agents. However, the role of such bridging agents is beyond the remit of this paper and this decision should be made along with the responsible consultant interventional cardiologist on a case-by-case basis [19].

Bare metal stents (BMS), which only require one month of DAPT, are now much less frequently used and the national BCIS audit shows they are used in less than $15 \%$ of cases in the UK, and many units no longer even stock them. Their main indication is for use in patients with a high bleeding risk or requiring urgent major surgery. Many UK units now use BioFreedom DES, these are polymer-free drug coated stents, which have a license of one month of DAPT and are superior to BMS with respect to major safety endpoints including bleeding and restenosis rates [20]. Finally there is increasing evidence that with a number of third generation DESs one month of DAPT can safely be used in patients at high bleeding risk without an increase in ischaemic events [21-23]. A single antiplatelet agent is continued in all cases after discontinuation of DAPT, this tends to be aspirin. In some cases, for example patients with previous stroke, the 
patients may have aspirin stopped at the end of the DAPT course and clopidogrel continued long-term. The important issue of a single antiplatelet agent in patients on long-term DOACs is discussed in the previous section.

Finally, in patients on a DOAC for atrial fibrillation and stroke prophylaxis who need DAPT after stent implantation, evidence from trials such as the RE-DUAL trial indicate that much shorter courses of triple therapy followed by a course of DOAC and clopidogrel alone are safer than previous practice of triple therapy up to a year [24]. The European Society of Cardiology and NICE guidelines, for both ACS and elective stenting, now support shorter durations of triple therapy followed by a DOAC and clopidogrel as the current standard of care $[10,25,26]$.

The duration of DAPT post PCI may also depend on a number of other factors, beyond the scope of this guideline. Therefore, in patients with coronary stents, we recommend that the endoscopist discusses the plan, with respect to potential DAPT cessation, with a consultant interventional cardiologist. Ideally this should be the consultant interventional cardiologist responsible for the patient's care, who did the stent procedure.

\section{Anticoagulants}

\section{Warfarin and heparin}

For low-risk endoscopic procedures we suggest that warfarin therapy should be continued (low quality evidence, moderate recommendation). It should be ensured that the INR does not exceed the therapeutic range in the week prior to the procedure (low quality evidence, strong recommendation).

- Tell the patient to continue warfarin and check the international normalized ratio (INR) during the week before the endoscopy;

- If the INR result is within the therapeutic range then continue with the usual daily dose;

- If the INR result is above the therapeutic range, but less than 5 , then reduce the daily warfarin dose until the INR returns to within the therapeutic range;

- If the INR is greater than 5 then defer the endoscopy and contact the anticoagulation clinic, or a medical practitioner, for advice.

For high-risk endoscopic procedures in patients at low thrombotic risk, we recommend discontinuing warfarin for 5 days before the procedure (strong recommendation, high quality evidence). Check INR prior to the procedure to ensure $<1.5$ (strong recommendation, low quality evidence).

- Stop warfarin for 5 days before the endoscopy;

- Check the INR prior to the procedure to ensure its value is $<1.5$;

- On the day of the procedure restart warfarin with the usual daily dose that night;

- Check INR one week later to ensure adequate anticoagulation.

For high-risk endoscopic procedures in patients at high thrombotic risk, we recommend that warfarin should be temporarily discontinued and substituted with low molecular weight hepar- in $(\mathrm{LMWH})$ (moderate quality evidence, strong recommendation).

- Warfarin should be stopped for 5 days before the procedure;

- Two days after stopping warfarin commence daily therapeutic dose of LMWH;

- Administer the last dose of LMWH at least 24 hours prior to the procedure;

- Check the INR prior to the procedure to ensure its value is $<1.5$;

- Warfarin can be resumed on the day of the procedure with the usual dose that night;

- Restart the daily therapeutic dose of LMWH on the day after the procedure;

- Continue LMWH until a satisfactory INR is achieved.

Updated literature searches were conducted on the use of warfarin and heparin in patients undergoing endoscopy. There were no new data to indicate a change to the existing protocols above. Any new data relevant to interventional therapy are discussed in the sections on specific endoscopic procedures.

\section{Direct oral anticoagulants}

For low-risk endoscopic procedures we suggest omitting the morning dose of DOACs on the day of the procedure (weak recommendation, low quality evidence).

For high-risk endoscopic procedures in patients on DOACs, we recommend that the last dose of DOACs be taken 3 days before the procedure (strong recommendation. low quality evidence). For patients on dabigatran with a $\mathrm{CrCl}$ (or eGFR) of 30$50 \mathrm{~mL} / \mathrm{min}$ we recommend that the last dose be taken 5 days prior to the procedure (strong recommendation, low quality evidence). In any patient with rapidly deteriorating renal function a haematologist should be consulted (strong recommendation, low quality evidence).

Direct oral anticoagulants have been a major advance in anticoagulant therapy. Dabigatran is an inhibitor of thrombin, and rivaroxaban, apixaban and edoxaban inhibit factor $\mathrm{Xa}$. They do not need routine monitoring, and INR and activated partial thromboplastin time (aPTT) are unreliable indicators of anticoagulant activity. Unlike warfarin they have a rapid onset of action and full anticoagulant activity is established within 3 hours of the first dose. They have relatively short half-lives, but these may be prolonged in renal failure, particularly for dabigatran. In patients undergoing a high-risk procedure with a low thrombotic risk we recommend that the last dose of rivaroxaban, apixaban or edoxaban is taken 3 days before the procedure. Dabigatran may have to be stopped for longer than this, however, when renal function is significantly reduced [27].

For patients on dabigatran with creatinine clearance $(\mathrm{CrCl})$ of $30-50 \mathrm{~mL} / \mathrm{min}$ we recommend that the last dose of the drug is 3-5 days before the procedure. Dabigatran therapy is contraindicated in patients with $\mathrm{CrCl}<30 \mathrm{~mL} / \mathrm{min}$. Estimated glomerular filtration rate (eGFR) is a suitable alternative measurement of renal function, and the same numerical values apply for the purposes of these guidelines. If a patient on any DOAC is clinically deteriorating, his/her renal function should be checked before the procedure. These recommendations are 
supported by the findings of the PAUSE trial.[5] Three thousand and seven patients on apixaban, dabigatran or rivaroxaban due for elective interventional procedures had a standardised interruption of therapy ( $\mathbf{F i g . 3}$ ): last dose of drug 2 days before low risk procedures (including diagnostic $\mathrm{Gl}$ endoscopy) and 3 days before high risk procedures (including high risk therapeutic GI endoscopy; e. g., polypectomy). This was extended to last dose 5 days before a high risk procedure for dabigatran patients with $\mathrm{CrCL}<50 \mathrm{~mL} / \mathrm{min}$. Resumption of therapy occurred at 1 day after low bleeding risk procedures and 2 to 3 days after high bleeding risk procedures. Low rates of major bleeding or arterial thromboembolism were observed. Low rates of venous thromboembolism were also observed although this was not a primary study outcome. We have maintained the recommendation to omit the morning dose of DOAC prior to low-risk endoscopic procedures, although the PAUSE trial demonstrates the safety of omitting the DOAC for 1 day before a low risk endoscopic procedure if desired

\section{Bridging of anticoagulant therapy}

Unfractionated heparin (UFH) and low molecular weight heparin (LMWH) have short half lives compared to warfarin and can be employed as an anticoagulation "bridge" while warfarin is temporarily discontinued for endoscopic procedures considered to have a significant risk of hemorrhage. UFH is administered by continuous intravenous infusion and LMWH by subcutaneous injection once or twice daily. The former requires an inpatient stay in hospital while warfarin is discontinued, and then re-introduced, and also requires frequent monitoring of APTT; the latter can often be managed in an outpatient setting without monitoring of anticoagulation levels. Some cardiologists have a preference for UFH for bridging warfarin in patients with metal heart valves. A meta-analysis demonstrated higher rates of bleeding in patients with mechanical heart valves bridged with LMWH vs UFH, but numbers were small in the LMWH studies [28]. A small multicentre registry study found no difference in adverse events between patients bridged with UFH or LMWH in this context [29], and bridging with LMWH is now commonplace. Guidelines from the American Heart Association and American College of Cardiology do not recommend one strategy over the other [30]. Prosthetic metal heart valves in the mitral position are at particularly high risk of thrombosis if warfarin is temporarily discontinued for 5 to 7 days. Heparin bridging for patients with a bileaflet mechanical aortic valve replacement in the absence of AF is considered unnecessary in guidelines from the British Society of Haematology [31] and from the American College of Cardiology/American Heart Association [32], but it is recommended in guidelines from the ESC and the European Association for Cardio-Thoracic Surgery [33]. There are no high quality studies to inform us, and consequently levels of evidence are low quality in all three guidelines. We have now placed mechanical aortic valve replacement in the high risk category requiring bridging, in line with European guidelines, but this should be decided in conjunction with local cardiology or cardiothoracic surgery services given the uncertainty. This should always be discussed with the consultant cardiologist responsible for the patient's care.
The risk of thromboembolism with AF increases with additional cardiovascular factors such as hypertension, heart failure and diabetes and this risk has been quantified by the $\mathrm{CHADS}_{2}$ score (annual risk of stroke increasing from $1.9 \%$ with a score of 1 to $18.2 \%$ with a score of 6 ). This has been updated with the $\mathrm{CHA}_{2} \mathrm{DS}_{2}$ VASc scoring system in which the annual risk of stroke increases from $1.3 \%$ with a score of 1 to $15.2 \%$ with score of 9. A randomised, prospective, double-blind placebocontrolled trial was conducted in 1884 patients with AF undergoing a variety of operative procedures including approximately $50 \% \mathrm{Gl}$ endoscopy[34]. Patients were randomised to LMWH or placebo, and risk factors were well matched. $38 \%$ of the patients had $\mathrm{CHADS}_{2}$ scores $\leq 3, \leq 2 \%$ had mitral stenosis and $\leq 3.4 \%$ had $\mathrm{CHADS}_{2}$ scores of 5 or 6 . There was no significant difference in rates of thromboembolism between the LMWH and placebo groups, but there was a significant increase in major haemorrhagic events in the LMWH group vs placebo (3.2\% vs $1.3 \%$ ). Caution should be exercised when interpreting the results in the high-risk thromboembolic groups as the study was not designed or statistically powered to examine these categories. The previous BSG/ESGE guidelines[1] do not recommend bridging for non-valvular AF, ASGE guidelines [35] recommend bridging with $\mathrm{LMWH}$ for $\mathrm{CHA}_{2} \mathrm{DS}_{2} \mathrm{VASC} \geq 2$ and the APAGE/APSDE guidelines [36] recommend this for $\mathrm{CHA}_{2} \mathrm{DS}_{2}$ $V A S c \geq 5$. $\mathrm{CHADS}_{2}$ scores are unfortunately not directly equivalent to $\mathrm{CHA}_{2} \mathrm{DS}_{2} \mathrm{VASc}$ scores. Further research on the benefits of heparin bridging is required in high-risk non-valvular $A F$ patients on warfarin in order to determine the optimum approach, but it would be reasonable to consider bridging patients with $\mathrm{CHADS}_{2}$ scores $\geq 5$ as recommended by the British Society of Haematology [31]. This applies to patients with AF and a previous stroke or transient ischaemic attack (TIA), and 3 of the following factors: congestive cardiac failure, hypertension (>140/90 $\mathrm{mmHg}$ or on antihypertensive medication), age $>75$ years, or diabetes mellitus. Heparin bridging is also recommended for patients with AF who have had a stroke or TIA within 3 months.[31]

Bridging with LMWH has also been studied in patients on DOACs. In a German registry, heparin bridging vs no bridging led to a higher rate of major haemorrhage $(2.7 \%$ vs $0.5 \%, p=$ 0.01 ) with no reduction in thromboembolism [37]. In the RELY trial bridging of dabigatran with $\mathrm{LMWH}$ resulted in higher major haemorrhage rates compared to no bridging $(6.5 \%$ vs $1.8 \%, \mathrm{p}<0.001)$ with no difference in thrombosis rates between the groups [38].

In a Japanese study of 16,977 patients on warfarin or DOACs undergoing a variety of high risk endoscopy procedures a propensity matched analysis demonstrated a significant increase in post procedure Gl bleeding and thromboembolism in patients who were bridged with heparin [39]. It should be noted that all patients were bridged with UFH rather than LMWH. For colonoscopy in patients on warfarin who were bridged with $\mathrm{LMWH}$, several studies have demonstrated an increase in post polypectomy haemorrhage without a decrease in thromboembolic events [40-42]. Bridging with LMWH should, of course still be advocated for those patients on warfarin at high risk of thromboembolism ( $\vee$ Tab. 3 ), but patients should be advised of the 
increased risk of post-procedure haemorrhage. The safety of temporary cessation of DOAC therapy, without bridging, is supported by the findings of the PAUSE trial.[5]

Patients with a history of venous thromboembolism within 3 months of commencing anticoagulant therapy are at high risk of recurrent thrombosis if anticoagulation is interrupted. Most of these patients are now commenced on a DOAC rather than warfarin, and bridging would not be recommended. Ideally we should not interrupt anticoagulation in this high risk group due to the risk of thrombosis; an elective low risk procedure could be performed without interrupting anticoagulation if necessary, but it may be preferable to defer a high risk procedure beyond three months anticoagulation if safe to do so.

Patients with thrombophilia syndromes should be discussed with a haematologist. Factor $\mathrm{V}$ Leiden and the common prothrombin mutation F2G20210A are low-risk thrombophilias and bridging is not required. Patients with deficiencies of antithrombin, protein $\mathrm{C}$ or protein $\mathrm{S}$ are at higher risk of thrombosis, but in most of these patients bridging therapy will not be required.

\section{Endoscopic procedures}

Minor haemorrhage is not uncommon during therapeutic endoscopic procedures, but we have considered it to be clinically significant when haemoglobin value falls by more than $20 \mathrm{~g} / \mathrm{L}$, necessitates blood transfusion, or causes an unplanned hospital admission. Haemorrhage may be apparent at the time of endoscopy, or delayed up to two weeks following the procedure. For those in whom antithrombotic therapy is interrupted, the latter situation presents a higher risk, as therapy will usually have been recommenced within that period. There are relatively few studies of the risks of haemorrhage for endoscopic procedures in patients who continue antithrombotic therapy, therefore much of the data underlying the risk levels for these procedures applies to the baseline risk of haemorrhage without antithrombotic therapy ( $\triangleright$ Table 3 ).

\section{Diagnostic endoscopy and mucosal biopsy}

Diagnostic endoscopies, including mucosal biopsy sampling, confer a minimal risk of haemorrhage, and no severe haemorrhage has been reported in studies involving thousands of patients in total [43-47]. No increased risk of haemorrhage from biopsy has been found in studies of patients on aspirin, clopidogrel or warfarin $[48,49]$. A prospective case control study of patients taking antiplatelet or anticoagulant drugs, including DOACs, found no incidence of significant bleeding in either the antithrombotic or control group who had upper GI biopsies taken [50]. Only 19 of the 277 patients who continued antithrombotics were on DOACs. The approximate mean number of biopsies per patient was only two in either group in this study, and in all the above studies only small numbers of biopsies were taken. In a prospective registry study 119 patients were identified who had continuation of DOAC for endoscopy, and 29 patients had biopsies on continued DOAC [51]. There were 2 cases of non-major clinically significant haemorrhage and no cases of major haemorrhage. There is one case report of life-threatening bleeding following multiple biopsies for Barretts oesophagus in a patient on aspirin who was later found to have high grade dysplasia [52]. A prospective study of endoscopic practice in Italy [53] regarding adherence to the previous BSG/ESGE antithrombotic guidelines [1] found an increased incidence of haemorrhage in patients undergoing mucosal biopsies in whom DOAC therapy was continued compared to those in whom the morning dose was withheld as recommended in the guidelines (2/38 $5.2 \%$ vs $2 / 1141.7 \%$, respectively). However, numbers of cases were small, the study was not adequately powered to determine this issue, and the difference did not reach statistical significance.

The pharmacokinetic profile, and hence pharmacodynamic effect, of DOACs varies such that some individuals will have higher peak levels 2 to 6 hours after oral administration [54]. Consequently, at the time of an endoscopic biopsy the anticoagulant effect due to a DOAC is not accurately predictable. Due to this uncertainty regarding the level of anticoagulation on DOACs at the time of endoscopy, and the absence of reliable test of anticoagulation on these drugs, we continue to suggest omitting the dose of DOAC on the morning of the procedure to allow an adequate safety margin. This applies to both once daily and twice daily regimens.

\section{Resection of Gl polyps}

Polypectomy including endoscopic mucosal resection (EMR)

Studies of colonoscopic polypectomy have identified a risk of post polypectomy bleeding (PPB) of $0.07-1.7 \%$ [47, 55-58]. It is important to differentiate between immediate and delayed PPB, and also to identify the severity of bleeding; these factors are not always clear in the literature. Delayed PPB is of particular importance in patients in whom antithrombotic therapy has been interrupted, as bleeding will often occur once antithrombotics have been restarted. In a BSG audit of 20,085 colonoscopies in the UK, $52(0.26 \%)$ haemorrhages were reported, but only 3 (0.01\%) were major [59]. Data from the English National Bowel Cancer Screening Programme found an overall PPB rate of $1.14 \%$, with a rate of severe bleeding requiring transfusion of $0.08 \%$.[60]

Risk factors for PPB include polyp size [61] use of pure cutting current [62] and use of a non microprocessor-controlled current for endoscopic mucosal resection (EMR) [63]. Use of endoscopic clips or submucosal injection of diluted adrenaline may also reduce the risk of PPB [64,65], Caution is advised, however, when using clips prior to excision for pedunculated polyps as one RCT was closed prematurely due to complications: one perforation (1.5\%) and 3 mucosal burns (4.5\%) [66]. An RCT of cold- vs hot-snare polypectomy (341 vs 346 polyps respectively) of polyps $4-9 \mathrm{~mm}$ demonstrated no significant haemorrhage in the cold-snare group [67]. In all of these studies, patients on antiplatelet therapy or anticoagulation were excluded.

A number of studies have examined the risks of resection of small colonic polyps on continued antitcoagulant therapy. A single centre case series of 1,177 cold snare polypectomies 
compared PPB in those on antiplatelets or anticoagulants compared to those not on these drugs [68]. There was an increase in immediate bleeding, mostly in warfarin patients, but no significant difference in delayed bleeding (up to 2 weeks) between the groups. A retrospective study of 223 polypectomies $(<1 \mathrm{~cm}$, with or without diathermy) in 123 patients on continued warfarin therapy found a rate of haemorrhage requiring transfusion of $0.8 \%$. This was despite routine prophylactic clipping of polypectomies [69]. In a RCT (159 polyps $<1 \mathrm{~cm}$ in 70 patients) examining hot vs cold snaring of polyps in anticoagulated patients, the rate of immediate haemorrhage in the hot snare vs. the cold snare group was $23.0 \%$ vs $5.7 \%$, respectively, and that of delayed haemorrhage requiring intervention $14 \%$ vs $0 \%$, respectively [70]. A RCT compared cold polypectomy $<1 \mathrm{~cm}$ in patients on DOAC or warfarin bridged with UFH compared to cold polypectomy on continued anticoagulant.[71] The incidence of polypectomy-related major bleeding was high at $12.0 \%$ in the former group and $4.7 \%$ in the latter. The majority of patients in the study would not have not have been considered for bridging by British Society of Haematology guidelines [31], and LMWH would have been recommended for any that did qualify for bridging.

The risk of polypectomy on continued antiplatelet therapy has also been studied. Aspirin monotherapy has been found to be safe in colonoscopic polypectomy [72-74]. A double blind RCT included patients on clopidogrel therapy who required colonoscopy [75]. They were randomised at 7 days before procedure into either continuing with Clopidogrel $75 \mathrm{mg}$ daily or placebo until the morning of colonoscopy. If discontinued, clopidogrel was restarted after colonoscopy when oral intake was allowed. More than $90 \%$ of patients had polyps les than $1 \mathrm{~cm}$. There was no significant difference in immediate or delayed $\mathrm{PPB}$, or in cardiothrombotic events, between the two groups. These conclusions, however, need to be treated with some caution. Although the study aim was to examine the effect of clopidogrel, a high proportion of patients were on DAPT. The groups were well matched but numbers were relatively small to examine differences in an infrequent event, and the rate of PPB in the placebo group was higher than expected when compared with other studies of patients undergoing polypectomy not previously on antiplatelet agents. A meta-analysis [76] assessing the risks of immediate and PPB associated with continued clopidogrel use at time of polypectomy included the above trial. A total of 5 studies were identified which included 655 patients in the 'continuing clopidogrel' group and 6620 controls with interrupted clopidogrel therapy. There was an increased risk of PPB in the continuing clopidogrel group (Risk ratio $-1.96 \mathrm{Cl} 1.36-2.83 ; \mathrm{p}=0.0003)$. There was no significant difference in serious cardio thrombotic events occurring within 30 days of the procedure. In the above studies the great majority of polypectomies were $<1 \mathrm{~cm}$. Further research is required, particularly with respect to polypectomy on DAPT, but based on the above data, it may be safe to undertake polypectomy for polyps $<1 \mathrm{~cm}$ in size on clopidogrel monotherapy. To minimise the risk of PPB cold snare polypectomy may be advisable. Alternatively, temporarily substituting aspirin for clopidogrel may be desirable 7 days prior to colonoscopy.
In large case series of EMR, the incidence of immediate and delayed bleeding ranged between 3.7-11.3\% and 0.6-6.2\%, respectively $[63,77,78]$. For EMR of small lesions $(<1 \mathrm{~cm})$, however, PPB rates were similar to those reported following conventional polypectomy [78]. A retrospective cohort study did not find aspirin (continued till day of procedure) or P2Y12 receptor antagonists (stopped 5-7 days before EMR) to be significant factors associated with bleeding post EMR of colon neoplasia [79]. However only a small minority (aspirin $20 \%$ and clopidogrel $2 \%$ ) of patients were taking these medications. The rate of delayed post-EMR bleeding in the oesophagus is low (0.6 to $0.9 \%$ ), even in studies that include a high proportion of patients with a temporary cessation of antiplatelet therapy [80, 81]. In two retrospective observational studies of duodenal EMR, delayed bleeding was reported in 14/113 (12.3\%) [82] and $7 / 111$ patients $(6.3 \%$ )[80] despite the prophylactic use of endoclips in $82 \%$ of cases in the latter. There are conflicting studies on the use of prophylactic endoclips for EMR [83-85]. A cost-efficacy analysis concluded that prophylactic placement of endoscopic clips after polypectomy was a cost-effective strategy for patients receiving antiplatelet or anticoagulation therapy.[86] Prophylactic use of endoclips may therefore be advisable for EMR in patients on antithrombotics due to the increased risk of PPB.

\section{Endoscopic submucosal dissection}

There have been several studies of ESD on continuous low dose aspirin since the previous version of this guideline. One retrospective multicentre study [87] for colonic ESD, and 6 retrospective studies of gastric ESD [88-93], comparing continuation with interruption of aspirin, found no significant differences in delayed bleeding the two groups. This was confirmed by two meta-analyses which also reported that continuation of low dose aspirin does not increase the post procedure bleeding after ESD [94,95]. This was also observed in the group of patients under dual antiplatelet therapy in which aspirin was continued alone [88]. Furthermore, inappropriate discontinuation of anti-platelet agents was significantly associated with increased risk of thrombosis [90]. A meta-analysis found a thrombosis rate of $2.1 \%$ in the aspirin-interrupted vs. none in the aspirin-continued group of patients [95].

Continued thienopyridine (clopidogrel or prasugrel) or aspirin use did not increase delayed haemorrhage for gastric ESD in one retrospective study [92]. A non-randomised retrospective comparative study found, however, that continuation of any antithrombotic, or heparin bridging, increased the risk of haemorrage with gastric ESD [93]. The risk of haemorrhage following gastric ESD is increased with the number of antiplatelet agents taken or when antiplatelet drugs are combined with anticoagulation [96]. For colorectal ESD, antiplatelet agents except for aspirin alone were independent risk factors of delayed bleeding (OR 4.04, $95 \% \mathrm{Cl} 1.44-11.30, \mathrm{p}=0.008)$ in a retrospective multicentre study including $180 / 1189$ patients on antiplatelets [87].

In a large national database including 16,977 patients who underwent high-risk endoscopic procedures under oral anticoagulation, upper and lower GI ESD were found to be signifi- 
cantly associated with post procedure haemorrhage [39]. The delayed bleeding rate after ESD at any location has been found to be $16 \%$ in patients who have had warfarin or DOACs, including those with heparin bridging (UFH) [97]. A meta-analysis of ESD studies found a significant increase in delayed haemorrhage and an increase in thrombosis with heparin bridging compared to those who discontinued anticoagulation without bridging [94]. A meta-analysis focused on heparin bridging therapy (UFH) for gastric ESD patients on warfarin or DOACs found an increased risk of haemorrhage without any benefit in thrombosis [95]. Studies of colonic ESD on anticoagulants have included small numbers and retrospective analysis, and conflicting conclusions have been derived [87, 98,99]. Few data are available for oesophageal or duodenal ESD on antithrombotics. The risk of bleeding after esophageal ESD is lower at compared with other locations $[100,101]$, but one retrospective study found a significant higher readmission rate after oesophageal ESD for patients with history of antiplatelet or anticoagulant use (56.4\% vs $34.1 \%$; $P=0.01$ ) [102].

Several methods have been proposed to reduce the risk of haemorrhage after ESD including pharmacological (PPI), mechanical (clips, endoscopic hand sutures) and local topical (fibrin glue and polyglycolic acid sheets, hemostatic powder) techniques, and these should be particularly considered in patients on antithrombotic therapy.

\section{Endoscopic Retrograde Cholangiopancreatography (ERCP)}

In a meta-analysis (21 prospective studies; 16855 patients), the overall haemorrhage rate following endoscopic retrograde cholangiopancreatography (ERCP) was $1.3 \%$, with $71 \%$ of these being graded as moderate and $29 \%$ as severe; the mortality rate was $0.05 \%$ overall [103]. Post-ERCP haemorrhage is most frequently seen after endoscopic biliary sphincterotomy. An ESGE guideline on ERCP-related adverse events has suggested that patients should be considered to be at increased risk for post-sphincterotomy haemorrhage if at least one of the following factors is present: anticoagulant intake, platelet count $<50,000 / \mathrm{mm}^{3}$, cirrhosis, dialysis for end-stage renal disease, intraprocedural bleeding and low endoscopist experience [104]. There are a number of measures which can reduce the risk of haemorrhage at ERCP including avoidance of sphincterotomy prior to biliary stenting [105], and use of a blended current rather than pure-cutting current [106-108]. These, and other measures to reduce the risk of haemorrhage are discussed in previous ESGE guidelines [104, 105].

Two uncontrolled retrospective studies reported post-endoscopic sphincterotomy (ES) bleeding in 8 (19\%) of 43 patients under antiplatelet monotherapy or dual therapy, including only one significant episode of haemorrhage $[109,110]$. Controlled studies of bleeding following ES performed under antiplatelet therapy have failed to demonstrate an increase in patients taking antiplatelets at the time of ES vs controls, but studies were underpowered to show a difference [110-112]. A single retrospective study (762 patients) has compared post-ES bleeding rates in patients who discontinued antiplatelets for $>7$ days $(n=29),<7$ days $(n=83)$ or did not discontinue antiplate- lets $(n=49)$ [111]. The incidence of bleeding (defined as clinical evidence of bleeding or a drop in $\mathrm{Hb}>2 \mathrm{~g} / \mathrm{dL}$ ) was respectively $10.3 \%$ (delayed, $6.9 \%$ ), $6.0 \%$ (delayed, $2.4 \%$ ) and $16.3 \%$ (delayed, $14.3 \%$ ). The only significant association was between sustained antiplatelet use and the delayed type of post-ES bleeding. Of note, a majority of antiplatelet users were taking aspirin only. A retrospective study in which 50/191 patients undergoing ES were on aspirin, showed no statistically significant increase in haemorrhage in the aspirin group [113]. Haemorrhage following endoscopic sphincteroplasty has been reported in $0 \%$ to $8.6 \%$ of patients [114]. One small case series suggested that continued aspirin therapy may be safe [115], but there are no data on other antithrombotics. There are no data for biliary mechanical lithotripsy, cholangioscopy or electrohydraulic lithotripsy therapy in patients taking antiplatelets or anticoagulants.

\section{Ampullectomy}

A meta-analysis (29 studies, 1751 patients) reported that haemorrhage occurs in $10.6 \%$ of ampullectomies with approximately $25 \%$ and $5 \%$ requiring blood transfusion and non-conservative management, respectively [116]. Various measures to prevent haemorrhage have been studied, but more research is required to make definitive conclusions. A nonrandomized pilot study $(n=80)$ suggested that routinely closing the mucosal defect with clips following ampullectomy is effective to prevent delayed bleeding ( $5 \%$ vs. $22.5 \%, P=0.026$ ) [117]. A RCT has suggested that, compared with the Autocut mode, the Endocut mode may prevent immediate but not delayed bleeding in cases with tumors $>14 \mathrm{~mm}$; it causes more frequent crush artifacts [118]. Prophylactic argon plasma coagulation has been reported as effective in a retrospective study $(n=82)$ and ineffective in a RCT $(n=54)$ to prevent post-ampullectomy bleeding $[119,120]$. Submucosal injection prior to ampullectomy did not prevent bleeding in a RCT $(n=50)$ and a retrospective matched cohort analysis $(n=50)[121,122]$; furthermore it was associated with higher tumor recurrence rate and a shorter recurrence-free survival in the retrospective study [121]. There are no data on ampullectomy on anticoagulants or P2Y12 receptor antagonists as these are usually withdrawn. Given the high haemorrhage rate, withdrawal of aspirin should be considered on an individual basis depending on the risks of thrombosis.

\section{Endoscopic ultrasound-guided with fine-needle aspiration (EUS-FNA), and other interventions}

The incidence of haemorrhage following EUS-guided sampling has been analysed in several systematic reviews; the figure per thousand was 1.28 for EUS-FNA (51 studies, 10,941 patients) [123], 5.81 for EUS-fine needle biopsy (FNB) (51 studies, 5,330 patients)[124] and 6.63 for EUS-FNA of pancreatic cystic lesions (40 studies, 5,124 patients) [125]. Four studies reported on haemorrhage following EUS-guided sampling in patients prescribed antithrombotic agents [126-129]. The only significant differences were between patients on prophylactic low molecular weight heparin and controls [128]. In the largest study, however, no severe haemorrhage was found in patients 
who continued or discontinued antithrombotic therapy, and only one thromboembolic event occurred [129].

EUS-guided biliary drainage, an alternative to ERCP-guided biliary stenting, has been suggested to be safely feasible in patients with sustained use of antiplatelets and/or anticoagulants. In a retrospective study that included 41 patients on antiplatelets and/or anticoagulants (23 patients under DAPT, anticoagulant or a combination of antiplatelet and anticoagulant) and 154 controls, bleeding rates were not significantly different in the antiplatelet/anticoagulants and control groups ( $7.3 \%$ and $2.6 \%$, respectively) [130]. The safety of EUS-guided biliary drainage should however be confirmed in prospective studies, adequately powered to evidence a significant difference, before a recommendation can be made. Invasive therapeutic procedures such as EUS and cystgastrostomy or necrosectomy have a significant risk of major haemorrhage and should be considered as high risk for P2Y12 receptor antagonists or anticoagulants. The risk on aspirin is unknown.

\section{Endoscopic dilatation}

Review of studies which included greater than 100 patients with benign upper Gl strictures, either anastomotic, achalasia, post-ESD, eosinophilic, gastric outlet obstruction or mixed etiology, reveals a risk of haemorrhage well below $1 \%$ [131140]. A systematic review and meta-analysis of studies of endoscopic dilatation of gastroduodenal Crohn's disease strictures revealed a $2.1 \%$ per procedure risk of haemorrhage [141]. In a prospective study of dilatation in 55 patients with oesophageal carcinoma no clinically relevant haemorrhage was observed [142]. Dilatation for lower Gl strictures, either iatrogenic or related to inflammatory bowel disease, revealed no significant haemorrhage in prospective studies or larger retrospective case series (over 100 patients) [143-147]. No data were found regarding dilatation in malignant colonic strictures.

A study of the complications arising from 504 balloon dilations in 237 patients with achalasia revealed 4 (1.7\%) asymptomatic haematomas, but no clinically significant haemorrhage [148]. There were, however, 7 (3\%) perforations. In a RCT of pneumatic dilatation vs. laparoscopic myotomy for achalasia there were no reported haemorrhages but 8/108 (9.5\%) patients experienced perforation during the treatment course [149].

Dilatation of $\mathrm{Gl}$ strictures in the upper or lower Gl tract appears to be a low risk procedure, with the exception of Crohn's disease-related ileal strictures, and balloon dilatation for achalasia. There are no data, however, on dilatation of strictures on antiplatelets or anticoagulants. This, together with the inaccessibility of the site of haemorrhage for endoscopic haemostasis, has led us to continue to consider endoscopic dilatation as a high risk procedure on $\mathrm{P} 2 \mathrm{Y} 12$ receptor antagonists or anticoagulants.

\section{Endoscopic stenting}

There are no studies on endoscopic stenting at any site in the GI tract in patients taking antiplatelets or anticoagulants. Available data regarding haemorrhage risk, from RCTs, prospective, and mostly retrospective studies, are heterogeneous regarding details of the time interval from stent placement until clinically relevant haemorrhage occurred, In deciding whether stent insertion is a high or low risk procedure we considered haemorrhage within 7 days of insertion.

Previous reviews of risks associated with endoscopic stent insertion have been confounded by the variety of stents used and the evolution of stent design with time. With respect to esophageal self-expanding metal stents (SEMS), 8 recent studies of demonstrated a risk of $0 \%$ significant haemorrhage within 7 days of insertion [150-157]. However, studies including delayed haemorrhage showed a risk of $9 \%$ in an RCT comparing small-diameter stents with large-diameter stents and an $8 \%$ risk in a large retrospective series of 997 patients $[158,159]$. Causes of haemorrhage included aorta-esophageal fistula formation, and continued oozing from tumours $[154,160]$.

With respect to duodenal SEMS, large (>100 patients) and recent retrospective and prospective studies showed a haemorrhage risk within 7 days of less than 1\% [161-163]. The one exception was a retrospective study including 152 patients, whereby the safety and benefits of SEMS combined with chemotherapy were investigated: in total 4 patients $(2.6 \%)$ suffered from haemorrhage that requiring blood transfusion. Though none of these patients had concomitant chemotherapy, two thirds had coexisting biliary obstruction for which an intervention was simultaneously performed [164].

With respect to colonic SEMS, a large prospective series of 513 patients and 6 retrospective studies found the risk of clinically relevant haemorrhage within 7 days to be $0 \%$ [165-174]. A systematic review identifying 40 studies on SEMS for the management of emergency malignant large bowel obstruction identified 9 studies reporting on clinical relevant bleeding which occurred in $0.5 \%$ (8 out of 1474 patients) [175].

We have considered endoscopic stenting at all sites in the GI tract to be low risk for haemorrhage within 7 days. Patients on antithrombotics may be at increased risk of delayed haemorrhage, however.

\section{Percutaneous endoscopic gastrostomy (PEG)}

Minor haemorrhage around the wound site at PEG placement is usually short-lived. Severe haemorrhage is rare, and may be secondary to PEG tract bleeding, injuries to the gastric artery, splenic or mesenteric vein (massive retroperitoneal bleeding), or rectus sheath hematoma [176-178]. Rarely, laparotomy may be required as a result of puncturing of the gastric artery at the time of insertion [177].

The overall risk of haemorrhage for PEG placement was $1.5 \%$ in a case series of 950 patients [179]. There are few data on continued administration of antithrombotics at the time of PEG insertion. A meta-analysis showed continuing anti-platelet therapy such as clopidogrel may be safe.[180] A German retrospective study of PEG insertion with patients on UFH, phenprocoumon, LMWH, aspirin, clopidogrel and combinations showed no evidence of increased haemorrhage.[181] A further study concluded that giving aspirin or clopidogrel either 72 hours before or 48 hours after the procedure did not increase bleeding risk [182]. The above studies are, however, of inadequate quality to definitively demonstrate an effect due to the drugs 
studied. A large retrospective study of patients undergoing endoscopic procedures on anticoagulants included 2322 PEG performed on warfarin and 1484 on DOACs, with a risk of post-endoscopy bleeding of $2.0 \%$ and $1.2 \%$, respectively [39].

\section{Device-assisted enteroscopy}

Single-balloon, double-balloon and spiral enteroscopy devices are available. The risk of haemorrhage from enteroscopy has been reported at $0.2 \%-0.3 \%[183,184]$. Spiral enteroscopy was not associated with a risk of clinically significant haemorrhage in a small case series.[185] Double balloon enteroscopy is associated with a perforation rate of $0.1-0.4 \%[183,186]$ and this rises to $1.5 \%$ if polypectomy is performed [186]. In a retrospective single centre study of 420 patients undergoing double-balloon enteroscopy, it was noted that $13 \%$ were on anticoagulation [187]. Although the risk of bleeding may be low for diagnostic procedures, therapeutic procedure such as polypectomy would confer a high risk of haemorrhage on antithrombotics. Endoscopic therapy was performed in $47.1 \%$ of 257 double-balloon procedures in a UK case series [188].

\section{Oesophageal variceal banding}

Generally, variceal band ligation (VBL) is undertaken when there is recent or active bleeding. However, elective variceal banding may be necessary at surveillance. In a case-control study of bleeding following VBL $3.4 \%$ of patients had haemorrhage secondary to banding induced ulcerations [189]. In a study of 605 patients undergoing VBL, 21 (3.5\%) patients had spontaneous bleeding due to band slippages confirmed at endoscopy, and 11 died [189]. Multivariate analysis found no increased risk of bleeding in those on aspirin, although this applied to only $8 / 605$ patients

A study of planned VBL in cirrhotic patients, including 265 patients on LMWH, showed no increase in post-procedural haemorrhage or reduction in survival compared to those not on LMWH [190]. An uncontrolled case series of 5 patients undergoing elective VBL on continued warfarin observed no postbanding haemorrhage [191]. Placing no more than 6 bands per session may help reduce the risk of post-banding ulcer haemorrhage [192]. In a large retrospective series, the risk of haemorrhage in patients undergoing variceal banding on DOAC or warfarin was high for both groups at $19.2 \%$ and $25.9 \%$ respectively $p=0.49$ [39]. There are no studies of variceal band ligation in patients on $\mathrm{P} 2 \mathrm{Y} 12$ receptor antagonists.

\section{Ablative therapies}

Radiofrequency ablation (RFA) in the oesophagus is a well established treatment for dysplasia within Barretts oesophagus. A meta-analysis of studies of oesophageal RFA has found a rate of haemorrhage of $1 \%$.[193] RFA has been used to treat gastric antral vascular ectasia, but we have only small case studies to inform us, as demonstrated in a systematic review [194]. In one case series of 21 patients there was a $10 \%$ ulceration rate necessitating discontinuation of RFA therapy. We have therefore classified oesophageal and gastric RFA as high risk for hemorrhage with respect to $\mathrm{P} 2 \mathrm{Y} 12$ receptor antagonists and anticoagulants. There are no data on aspirin, but we advise continuation in ither procedures with similar rates of haemorrhage.

Argon plasma coagulation is used as an ablative therapy for a wide variety of indications throughout the Gl tract, including ablation of vascular abnormalities including angiodysplasia and radiation proctitis, ablation of tumours and margins of resected polyps, ablation of dysplastic Barretts oesophagus, and occasionally as a haemostatic measure. With different indications there is variation in size of the ablated mucosal field, energy delivered, and consequences including rarely perforation. There are no data on continued use of antithrombotics with respect to the risk of haemorrhage from APC, and we are therefore unable to provide specific guidance in this regard.

\section{Restarting antithrombotic therapy for elective procedures}

There are few data to inform us on the optimal time to restart antithrombotic therapy, if discontinued, after elective endoscopic therapy. Decisions in all cases will be based on the perceived risk of haemorrhage following the procedure versus the risk of thrombosis to an individual patient. It should be remembered that DOACs exert an anticoagulant effect within hours, compared to days for warfarin. Data from the PAUSE study indicates that restarting a DOAC 2-3 days after a high risk procedure has a low risk of thromboembolic events [5]. Data on restarting therapy after acute $\mathrm{Gl}$ haemorrhage are discussed in that section. A prospective cohort study in Italy [53] evaluated the risks of haemorrhage and thrombosis in relation to compliance with the previous version of this BSG/ESGE guideline. For cases who underwent polypectomy there was a trend to more intraprocedural bleeding if DOAC was not stopped as per the guideline for high-risk procedures. Stopping longer than the guidelines did not reduce the intraprocedural bleeding risk. Also, restarting the DOAC immediately after polypectomy, rather than a delay of $24-48 \mathrm{hrs}$ (as suggested by the guidelines) in high-risk patients led to an almost doubling of the delayed bleeding risk without a reduction in thrombosis, although these measures did not reach statistical significance.

For procedures with a very high risk of haemorrhage such as ESD, it may be desirable to delay restarting antithrombotics beyond the intervals recommended in these guidelines. In a meta-analysis, post-ESD bleeding risk was not significantly increased if antithrombotic therapy was resumed at least 1 week after ESD whereas resumption of antithrombotic therapy immediately or within 1 week after ESD was significantly associated with post-ESD bleeding [94]. The incidence of thrombosis was not analysed, however, and this needs to be considered on an individual patient basis.

\section{Risk stratification for elective endoscopic procedures}

Endoscopic procedures carry a higher risk of haemorrhage, and certain clinical situations will result in a high risk of thromboembolic complications should antiplatelets or anticoagulants be withdrawn. Procedures have been classified as highrisk or low-risk for haemorrhage primarily based on the risks of 
haemorrhage in patients not taking antiplatelets or anticoagulants, as well as some limited data available regarding endoscopy in patients in whom these drugs were continued ( $>$ Table 1). Tables 2 and 3 stratify risk for discontinuation of P2Y12 receptor antagonists or warfarin respectively according to clinical scenario, and the risks of thromboembolic sequelae on discontinuation of therapy.

Diagnostic endoscopic procedures, with or without biopsy, are classified as low-risk for haemorrhage, though there is concern regarding biopsy on DOACs. The likelihood of having to undertake therapy with a risk of haemorrhage should also be considered, for example colonoscopy when polyps have been found in 22.5-34.2\% of patients in large studies [47,55]. Endoscopists may therefore choose to manage colonoscopies as high-risk procedures with respect to P2Y12 receptor antagonists and anticoagulants. Similar considerations apply to ERCP if there is uncertainty as to whether sphincterotomy will be required.

\section{Acute Gl haemorrhage on antiplatelets and anticoagulants}

\section{Antiplatelets}

We suggest that permanent discontinuation of aspirin for primary prophylaxis should be considered (weak recommendation, low quality evidence).

We suggest that aspirin for secondary prevention should not be routinely stopped. If it is stopped, it should be recommenced as soon as haemostasis is achieved, or there is no further evidence of bleeding (strong recommendation, moderate quality evidence).

We recommend that dual antiplatelet therapy is continued if possible in patients with coronary stents in situ and management should be in liaison with a consultant interventional cardiologist (strong recommendation, moderate quality evidence). In the case of major haemorrhage we recommend continuing aspirin if the $\mathrm{P} 2 \mathrm{Y} 12$ receptor antagonist is interrupted (strong recommendation, moderate quality evidence). P2Y12 receptor antagonist therapy should be re-instated within 5 days, if still indicated (strong recommendation, moderate quality evidence).

Antiplatelets confer an increased risk of spontaneous haemorrhage, but also present an increased risk to the patient when this occurs. In the case of life-threatening haemorrhage, this is of urgent concern, but withdrawal of antiplatelet therapy confers a risk of thrombosis. A meta-analysis of studies of patients on aspirin for secondary prophylaxis found that discontinuation of aspirin was associated with a 3 -fold increased risk of major adverse cardiac events, increasing to an odds ratio of 89 for major cardiac events in patients with coronary stents [6]. If $\mathrm{Gl}$ haemorrhage occurs in a patient with a recently placed coronary stent on DAPT, then life-threatening thrombosis could occur if therapy is interrupted. The imperative, after adequate resuscitation, is to achieve haemostasis within the Gl tract and urgent facilities should be available to provide this. Liaison with a consultant interventional cardiologist should occur in the emergency setting. If it is deemed necessary to temporarily discontinue antiplatelet therapy, this should be limited to the P2Y12 receptor antagonist, and aspirin continued [195]. The timing of restarting antithrombotic therapy after acute GI haemorrhage will be determined by the risk of re-bleeding and the risk of acute thrombosis without antithrombotic therapy [196]. P2Y12 receptor antagonists in patients with coronary stents should be restarted within a maximum of 5 days due to the high risk of stent thrombosis after this time. This timeframe represents an optimal balance between haemorrhage and thrombosis [195], though it has not been tested prospectively.

For patients on aspirin monotherapy for secondary prophylaxis, there is a benefit to continued therapy. A prospective placebo-controlled RCT of 156 patients following endoscopically controlled upper GI haemorrhage, demonstrated a reduction in all-cause mortality in the group receiving low-dose aspirin (1.3\% vs $12.9 \%$ ) [197]. There was an excess of bleeds in the aspirin group (10.3\% vs $5.4 \%$ ) but none were fatal. 5 patients in the placebo arm died of thromboembolic events. If aspirin is stopped then it should be reintroduced as soon as haemostasis has been achieved.

A retrospective study of 118 patients on antiplatelets or anticoagulants presenting with acute $\mathrm{GI}$ haemorrhage compared outcomes in those who had antithrombotic therapy permanently discontinued compared to those in whom it was restarted [198]. In those in whom antithrombotic therapy was discontinued the hazard ratio for thrombotic events was 5.77 (95\%Cl 1.26-26.35) and for mortality 3.32 (1.07-10.31) compared to those in whom it was restarted. It is therefore important to have a plan for consideration of restarting antithrombotic therapy in all such patients presenting with GI haemorrhage.

\section{Anticoagulants}

We recommend withholding oral anticoagulant and correcting coagulopathy according to the severity of haemorrhage and the patient's thrombotic risk in coordination with a consultant cardiologist/haematologist. The correction of coagulopathy should not delay endoscopy or radiologic intervention (strong recommendation, low quality evidence).

In patients with haemodynamic instability who take vitamin $\mathrm{K}$ antagonists (VKAs), we recommend administering intravenous vitamin $\mathrm{K}$ and four-factor prothrombin complex concentrate (PCC) (strong recommendation, low quality evidence), or fresh frozen plasma if PCC is not available (weak recommendation, very low quality evidence)

In patients with haemodynamic instability who take DOACs, we suggest considering the use of reversal agents: idarucizumab in dabigatran patients, and andexanet in anti-factor Xa treated patients (weak recommendation, low quality evidence), or intravenous four-factor PCC if andexanet is not available (weak recommendation, very low quality evidence)

We recommend restarting anticoagulation following acute GI haemorrhage in patients with an indication for long-term anticoagulation (strong recommendation, low quality evidence). In patients at low thrombotic risk, we suggest restarting anticoagulation as soon as possible after seven days of anticoagulant interruption (weak recommendation, low quality evi- 
dence). In those at high-thrombotic risk, an earlier resumption of anticoagulation with heparin bridging, preferably within 3 days, is recommended (strong recommendation, low quality evidence).

Anticoagulant use is reported in up to $15 \%$ and $25 \%$ of patients presenting with acute upper and lower Gl bleeding, respectively [199-201]. Gl bleeding-related mortality in these patients is high (up to $8-12 \%$ ), but mainly related to patients' comorbidities. Anticoagulants are independent predictors of neither mortality nor in-hospital rebleeding [202-205], provided they are managed appropriately. Temporary discontinuation of anticoagulation is the "standard of care" in patients with clinically significant GI bleeding [206, 207].

The anticoagulant effect of Vitamin $\mathrm{K}$ antagonists (VKA) such as warfarin can persist for 3-5 days. The need for a rapid correction of VKA-related coagulopathy with reversal agents mainly depends on the severity of haemorrhage, but their use requires caution in patients at high thrombotic risk (e.g. mechanical heart valve) since their use has been associated with thromboembolism [208]. Vitamin K takes several hours to correct anticoagulation, so the use of 4-factor Prothrombin Complex Concentrate (PCC) may be necessary to rapidly reverse anticoagulation in patients with active bleeding and haemodynamic instability. PCC is preferred over FFP, for a lower volume load, faster onset of action, and no need to check the patient's blood group. Concomitant low-dose vitamin $\mathrm{K}$ is recommended in this situation to prevent an "INR rebound".

Unlike VKAs, DOACs are characterized by a relatively short half-lives, so that their anticoagulant activity usually rapidly wanes-off over 12-24 hours. Consequently, most cases of major GI haemorrhage can be managed by withholding the drug and waiting for the anticoagulant effects to resolve. In hemodynamically unstable patients, acute reversal of anticoagulation may be required [209, 210]. Vitamin K, FFP, and protamine administration are ineffective. Idarucizumab, a humanized antibody fragment that neutralizes the effect of dabigatran, is now currently available as first-line reversal agent in dabigatran patients presenting with life-threatening/ uncontrolled bleeding $[211,212]$. Idarucizumab reverses dabigatran-related coagulopathy rapidly (within a few minutes) and persistently (for about 24 hours) in more than $98 \%$ of the patients, with a low thrombotic complication rate ( $6 \%$ at 90 days). Andexanet alfa, an inactive form of factor-Xa (FXa) that neutralizes circulating FXa inhibitors, has recently been approved as an antidote to apixaban and rivaroxaban in patients with life threatening haemorrhage, but its clinical use is hindered by its limited availability, the prohibitive cost, and safety concern about possible procoagulant effect [213]. 4-factor PCC at fixed dose (2000IU) may represent an alternative to andexanet alpha, with lower thromboembolic risk, but uncertain efficacy [214-216].

Correction of coagulopathy, when required, should not delay urgent endoscopic or radiological interventions when indicated, as these procedures can be safely and effectively performed at therapeutic levels of anticoagulation in the context of acute haemorrhage [217,218].

After bleeding cessation, observational studies [219-222] and two meta-analyses $[223,224]$ consistently indicate there is a net clinical benefit of restarting anticoagulation, due to a reduced risk of thromboembolism and death, despite an increased risk of rebleeding. However, evidence on the optimal timing for restarting anticoagulation is limited. A single retrospective study indicates an excess risk of Gl bleeding and of thromboembolism for an interval of warfarin interruption shorter than 7 days and longer than 30 days, respectively [219]. Since there is a trend toward a reduced incidence of thromboembolic events the earlier warfarin is introduced, it is reasonable to restart warfarin as soon as possible by day seven following its interruption. Data on the optimal timing of DOAC resumption are lacking. In analogy with warfarin, restarting DOACs as soon as possible by day seven after their interruption seems reasonable in most cases. The DOAC rapid onset of action, resulting in a full anticoagulation within 2-4 hours, warrants some caution with an earlier resumption.

In patients at very high thrombotic risk (e. g. prosthetic metal heart valve in mitral position), cardiology societies recommend an earlier resumption of anticoagulation with UFH in those at highest risk, rapid titration of prophylactic doses of LMWH to therapeutic doses within 48-72 hours [209,210]. The choice of strategy should be discussed with the patient's cardiologist. If the risk of restarting anticoagulation is estimated to outweigh the benefits, a consultation with the referral specialist (hematologist, neurologist, and/or cardiologist) is advisable, and alternatives to anticoagulation, such as a left atrial appendage occlusion in AF, or inferior vena cava filter for acute deep venous thrombosis (DVT), may be considered [209, 210].

\section{Disclaimer}

These joint BSG and ESGE guidelines represent a consensus of best practice based on the available evidence at the time of preparation. They may not apply in all situations and should be interpreted in the light of specific clinical situations and resource availability. Further controlled clinical studies may be needed to clarify aspects of these statements, and revision may be necessary as new data appear. Clinical consideration may justify a course of action at variance to these recommendations, but we suggest that reasons for this are documented in the medical record. BSG and ESGE guidelines are intended to be an educational device to provide information that may assist endoscopists in providing care to patients. They are not rules and should not be construed as establishing a legal standard of care or as encouraging, advocating, requiring, or discouraging any particular treatment.

\section{Acknowledgements}

We gratefully acknowledge the contribution of Dr Sanne Hoogenboom from the Academic Medical Centre, Amsterdam, who undertook the literature searches for risks associated with endoscopic dilatation and endoscopic stenting. We are indebted to Professor Tony Gershlick, an interventional cardiologist who made a major contribution to the antiplatelet advice in the 2008 and 2016 versions of this guideline, and which 
underpin the recommendations in this update. Professor Gershlick sadly died due to Covid-19 before being able to contribute to this updated document.

\section{Competing interests}

Dr Radaelli has received speaker fees from Bristol-Meyers Squibb, Pfizer and Boehringer Ingelheim. Dr Alikhan has received fees from Alexion, Bayer, Boehringer Ingelheim, Bristol-Meyers Squibb, Daiichi, Pfizer and Portola. Dr Lester has received speaker fees from Sanofi Aventis and Leo Pharma, speaker fees and advisory board fees from Bayer, Daichii Sankyo, Pfizer, and Boehringer Ingelheim, and support to attend a scientific meeting from Boehringer Ingelheim. Prof VanHooft has received departmental research grant support from Cook Medical and Abbott, lecture fees from Medtronics and Cook Medical, and consultancy fees from Boston Scientific and Olympus. None of the remaining authors have competing interests to declare.

\section{References}

[1] Veitch AM, Vanbiervliet G, Gershlick AH et al. Endoscopy in patients on antiplatelet or anticoagulant therapy, including direct oral anticoagulants: British Society of Gastroenterology (BSG) and European Society of Gastrointestinal Endoscopy (ESGE) guidelines. Gut 2016; 65: 374-389

[2] Veitch AM, Vanbiervliet G, Gershlick AH et al. Endoscopy in patients on antiplatelet or anticoagulant therapy, including direct oral anticoagulants: British Society of Gastroenterology (BSG) and European Society of Gastrointestinal Endoscopy (ESGE) guidelines. Endoscopy 2016; 48: 385-402

[3] AGREE Next Steps Consortium. The AGREE II Instrument (Electronic version). 2009: Available at (Accessed May 2021): http://www. agreetrust.org

[4] Guyatt GH, Oxman AD, Vist GE et al. GRADE: an emerging consensus on rating quality of evidence and strength of recommendations. Bmj 2008; 336: 924-926

[5] Douketis JD, Spyropoulos AC, Duncan J et al. Perioperative Management of Patients With Atrial Fibrillation Receiving a Direct Oral Anticoagulant. JAMA internal medicine 2019; 179: 1469-1478

[6] Biondi-Zoccai GG, Lotrionte M, Agostoni P et al. A systematic review and meta-analysis on the hazards of discontinuing or not adhering to aspirin among 50,279 patients at risk for coronary artery disease. European heart journal 2006; 27: 2667-2674

[7] Maulaz AB, Bezerra DC, Michel P et al. Effect of discontinuing aspirin therapy on the risk of brain ischemic stroke. Archives of neurology 2005; 62: 1217-1220

[8] Oscarsson A, Gupta A, Fredrikson M et al. To continue or discontinue aspirin in the perioperative period: a randomized, controlled clinical trial. British journal of anaesthesia 2010; 104: 305-312

[9] Yasuda S, Kaikita K, Akao M et al. Antithrombotic Therapy for Atrial Fibrillation with Stable Coronary Disease. The New England journal of medicine 2019; 381: 1103-1113

[10] Knuuti J, Wijns W, Saraste A et al. 2019 ESC Guidelines for the diagnosis and management of chronic coronary syndromes. European heart journal 2020; 41: 407-477

[11] Gori T, Polimeni A, Indolfi C et al. Predictors of stent thrombosis and their implications for clinical practice. Nature reviews Cardiology 2019; 16: 243-256

[12] Lopes RD, Heizer G, Aronson R et al. Antithrombotic Therapy after Acute Coronary Syndrome or PCI in Atrial Fibrillation. The New England journal of medicine 2019; 380: 1509-1524
[13] Dasa O, Pepine C], Pearson TA. Aspirin in Primary Prevention: What Changed? A Critical Appraisal of Current Evidence. The American journal of cardiology 2021; 141: 38-48

[14] Budaj A, Yusuf S, Mehta SR et al. Benefit of clopidogrel in patients with acute coronary syndromes without ST-segment elevation in various risk groups. Circulation 2002; 106: 1622-1666

[15] Korte W, Cattaneo M, Chassot PG et al. Peri-operative management of antiplatelet therapy in patients with coronary artery disease: joint position paper by members of the working group on Perioperative Haemostasis of the Society on Thrombosis and Haemostasis Research (GTH), the working group on Perioperative Coagulation of the Austrian Society for Anesthesiology, Resuscitation and Intensive Care (OGARI) and the Working Group Thrombosis of the European Society for Cardiology (ESC). Thrombosis and haemostasis 2011; 105: 743-749

[16] lakovou I, Schmidt T, Bonizzoni E et al. Incidence, predictors, and outcome of thrombosis after successful implantation of drug-eluting stents. Jama 2005; 293: 2126-2130

[17] Olier I, Sirker A, Hildick-Smith DJR et al. Association of different antiplatelet therapies with mortality after primary percutaneous coronary intervention. Heart 2018; 104: 1683-1690

[18] Schupke S, Neumann F], Menichelli M et al. Ticagrelor or Prasugrel in Patients with Acute Coronary Syndromes. The New England journal of medicine 2019; 381: 1524-1534

[19] Valgimigli M, Bueno H, Byrne RA et al. 2017 ESC focused update on dual antiplatelet therapy in coronary artery disease developed in collaboration with EACTS: The Task Force for dual antiplatelet therapy in coronary artery disease of the European Society of Cardiology (ESC) and of the European Association for Cardio-Thoracic Surgery (EACTS). European heart journal 2018; 39: 213-260

[20] Urban P, Meredith IT, Abizaid A et al. Polymer-free Drug-Coated Coronary Stents in Patients at High Bleeding Risk. The New England journal of medicine 2015; 373: 2038-2047

[21] Kandzari DE, Kirtane AJ, Windecker S et al. One-Month Dual Antiplatelet Therapy Following Percutaneous Coronary Intervention With Zotarolimus-Eluting Stents in High-Bleeding-Risk Patients. Circulation Cardiovascular interventions 2020; 13: e009565

[22] Varenne O, Cook S, Sideris G et al. Drug-eluting stents in elderly patients with coronary artery disease (SENIOR): a randomised single-blind trial. Lancet 2018; 391: 41-50

[23] Watanabe H, Domei T, Morimoto T et al. Effect of 1-Month Dual Antiplatelet Therapy Followed by Clopidogrel vs 12-Month Dual Antiplatelet Therapy on Cardiovascular and Bleeding Events in Patients Receiving PCI: The STOPDAPT-2 Randomized Clinical Trial. Jama 2019; 321: 2414-2427

[24] Cannon CP, Bhatt DL, Oldgren J et al. Dual Antithrombotic Therapy with Dabigatran after $\mathrm{PCl}$ in Atrial Fibrillation. The New England journal of medicine 2017; 377: 1513-1524

[25] Collet JP, Thiele H, Barbato E et al. 2020 ESC Guidelines for the management of acute coronary syndromes in patients presenting without persistent ST-segment elevation. European heart journal 2021; 42: $1289-1367$

[26] Ibanez B, James S, Agewall S et al. 2017 ESC Guidelines for the management of acute myocardial infarction in patients presenting with ST-segment elevation: The Task Force for the management of acute myocardial infarction in patients presenting with ST-segment elevation of the European Society of Cardiology (ESC). European heart journal 2018; 39: 119-177

[27] Schulman S, Carrier M, Lee AY et al. Perioperative Management of Dabigatran: A Prospective Cohort Study. Circulation 2015; 132: $167-173$ 
[28] Passaglia LG, de Barros GM, de Sousa MR. Early postoperative bridging anticoagulation after mechanical heart valve replacement: a systematic review and meta-analysis. Journal of thrombosis and haemostasis : JTH 2015; 13: 1557-1567

[29] Spyropoulos AC, Turpie AG, Dunn AS et al. Perioperative bridging therapy with unfractionated heparin or low-molecular-weight heparin in patients with mechanical prosthetic heart valves on longterm oral anticoagulants (from the REGIMEN Registry). The American journal of cardiology 2008; 102: 883-889

[30] Otto CM, Nishimura RA, Bonow RO et al. 2020 ACC/AHA Guideline for the Management of Patients With Valvular Heart Disease: A Report of the American College of Cardiology/American Heart Association Joint Committee on Clinical Practice Guidelines. Circulation 2021; 143: e72-e227

[31] Keeling D, Tait RC, Watson $\mathrm{H}$ et al. Peri-operative management of anticoagulation and antiplatelet therapy. British journal of haematology 2016; 175: 602-613

[32] Nishimura RA, Otto CM, Bonow RO et al. 2017 AHA/ACC Focused Update of the 2014 AHA/ACC Guideline for the Management of Patients With Valvular Heart Disease: A Report of the American College of Cardiology/American Heart Association Task Force on Clinical Practice Guidelines. Journal of the American College of Cardiology 2017; 70: 252-289

[33] Baumgartner H, Falk V, Bax J] et al. 2017 ESC/EACTS Guidelines for the management of valvular heart disease. European heart journal 2017; 38: 2739-2791

[34] Douketis JD, Spyropoulos AC, Kaatz S et al. Perioperative Bridging Anticoagulation in Patients with Atrial Fibrillation. The New England journal of medicine 2015; 373: 823-833

[35] Acosta RD, Abraham NS, Chandrasekhara V et al. The management of antithrombotic agents for patients undergoing $\mathrm{Gl}$ endoscopy. Gastrointestinal endoscopy 2016; 83: 3-16

[36] Chan FKL, Goh KL, Reddy N et al. Management of patients on antithrombotic agents undergoing emergency and elective endoscopy: joint Asian Pacific Association of Gastroenterology (APAGE) and Asian Pacific Society for Digestive Endoscopy (APSDE) practice guidelines. Gut 2018; 67: 405-417

[37] Beyer-Westendorf J, Gelbricht V, Forster K et al. Peri-interventional management of novel oral anticoagulants in daily care: results from the prospective Dresden NOAC registry. European heart journal 2014; 35: 1888-1896

[38] Douketis JD, Healey JS, Brueckmann M et al. Perioperative bridging anticoagulation during dabigatran or warfarin interruption among patients who had an elective surgery or procedure. Substudy of the RE-LY trial. . Thrombosis and haemostasis 2015; 113: 625-632

[39] Nagata N, Yasunaga $H$, Matsui $H$ et al. Therapeutic endoscopy-related Gl bleeding and thromboembolic events in patients using warfarin or direct oral anticoagulants: results from a large nationwide database analysis. Gut 2018; 67: 1805-1812

[40] Ishigami H, Arai M, Matsumura T et al. Heparin-bridging therapy is associated with a high risk of post-polypectomy bleeding regardless of polyp size. Digestive endoscopy : official journal of the Japan Gastroenterological Endoscopy Society 2017; 29: 65-72

[41] Lin D, Soetikno RM, McQuaid K et al. Risk factors for postpolypectomy bleeding in patients receiving anticoagulation or antiplatelet medications. Gastrointestinal endoscopy 2018; 87: 1106-1113

[42] Ono S, Ishikawa M, Matsuda K et al. Clinical impact of the perioperative management of oral anticoagulants in bleeding after colonic endoscopic mucosal resection. BMC gastroenterology 2019; 19 : 206

[43] Macrae FA, Tan KG, Williams CB. Towards safer colonoscopy: a report on the complications of 5000 diagnostic or therapeutic colonoscopies. Gut 1983; 24: 376-383
[44] Reiertsen O, Skjoto J, Jacobsen CD et al. Complications of fiberoptic gastrointestinal endoscopy-five years' experience in a central hospital. Endoscopy 1987; 19: 1-6

[45] Rogers BH, Silvis SE, Nebel OT et al. Complications of flexible fiberoptic colonoscopy and polypectomy. Gastrointestinal endoscopy 1975; $22: 73-77$

[46] Vu CK, Korman MG, Bejer I et al. Gastrointestinal bleeding after cold biopsy. The American journal of gastroenterology 1998; 93: 11411143

[47] Wexner SD, Garbus JE, Singh J] et al. A prospective analysis of 13,580 colonoscopies. Reevaluation of credentialing guidelines. Surgical endoscopy 2001; 15: 251-261

[48] Ono S, Fujishiro M, Kodashima S et al. Evaluation of safety of endoscopic biopsy without cessation of antithrombotic agents in Japan. Journal of gastroenterology 2012; 47: 770-774

[49] Whitson M], Dikman AE, von Althann C et al. Is gastroduodenal biopsy safe in patients receiving aspirin and clopidogrel? a prospective, randomized study involving 630 biopsies. Journal of clinical gastroenterology 2011; 45: 228-233

[50] Yuki T, Ishihara S, Yashima K et al. Bleeding Risk Related to Upper Gastrointestinal Endoscopic Biopsy in Patients Receiving Antithrombotic Therapy: A Multicenter Prospective Observational Study. Curr Ther Res Clin Exp 2017; 84: 32-36

[51] Heublein V, Pannach S, Daschkow K et al. Gastrointestinal endoscopy in patients receiving novel direct oral anticoagulants: results from the prospective Dresden NOAC registry. Journal of gastroenterology 2018; 53: 236-246

[52] Mannath J, Subramanian V, Kaye PV et al. Life-threatening bleeding following Barrett's surveillance biopsies. Endoscopy 2010; 42: (Suppl. 02): E211-212

[53] Radaelli F, Fuccio L, Paggi S et al. Periendoscopic management of direct oral anticoagulants: a prospective cohort study. Gut 2019; 68: 969-976

[54] Baglin T. Clinical use of new oral anticoagulant drugs: dabigatran and rivaroxaban. British journal of haematology 2013; 163: 160-167

[55] Bowles C], Leicester R, Romaya C et al. A prospective study of colonoscopy practice in the UK today: are we adequately prepared for national colorectal cancer screening tomorrow? Gut 2004; 53: 277283

[56] Gibbs DH, Opelka FG, Beck DE et al. Postpolypectomy colonic hemorrhage. Diseases of the colon and rectum 1996; 39: 806-810

[57] Rosen L, Bub DS, Reed JF et al. Hemorrhage following colonoscopic polypectomy. Diseases of the colon and rectum 1993; 36: $1126-$ 1131

[58] Sieg A, Hachmoeller-Eisenbach U, Eisenbach T. Prospective evaluation of complications in outpatient $\mathrm{Gl}$ endoscopy: a survey among German gastroenterologists. Gastrointestinal endoscopy 2001; 53: 620-627

[59] Gavin DR, Valori RM, Anderson JT et al. The national colonoscopy audit: a nationwide assessment of the quality and safety of colonoscopy in the UK. Gut 2013; 62: 242-249

[60] Rutter MD, Nickerson C, Rees C] et al. Risk factors for adverse events related to polypectomy in the English Bowel Cancer Screening Programme. Endoscopy 2014; 46: 90-97

[61] Sawhney MS, Salfiti N, Nelson DB et al. Risk factors for severe delayed postpolypectomy bleeding. Endoscopy 2008; 40: 115-119

[62] Kim HS, Kim TI, Kim WH et al. Risk factors for immediate postpolypectomy bleeding of the colon: a multicenter study. The American journal of gastroenterology 2006; 101: 1333-1341

[63] Burgess NG, Metz AJ, Williams S] et al. Risk factors for intraprocedural and clinically significant delayed bleeding after wide-field endoscopic mucosal resection of large colonic lesions. Clin Gastroenterol Hepatol 2014; 12: 651-661 e1-3 
[64] Corte C], Burger DC, Horgan G et al. Postpolypectomy haemorrhage following removal of large polyps using mechanical haemostasis or epinephrine: a meta-analysis. United European gastroenterology journal 2014; 2: 123-130

[65] Li LY, Liu QS, Li L et al. A meta-analysis and systematic review of prophylactic endoscopic treatments for postpolypectomy bleeding. International journal of colorectal disease 2011; 26: 709-719

[66] Quintanilla E, Castro JL, Rabago LR et al. Is the use of prophylactic hemoclips in the endoscopic resection of large pedunculated polyps useful? A prospective and randomized study. Journal of interventional gastroenterology 2012; 2: 183-188

[67] Kawamura T, Takeuchi Y, Asai S et al. A comparison of the resection rate for cold and hot snare polypectomy for 4-9 mm colorectal polyps: a multicentre randomised controlled trial (CRESCENT study). Gut 2018; 67: 1950-1957

[68] Arimoto ], Chiba H, Ashikari K et al. Safety of Cold Snare Polypectomy in Patients Receiving Treatment with Antithrombotic Agents. Digestive diseases and sciences 2019; 64: 3247-3255

[69] Friedland S, Sedehi D, Soetikno R. Colonoscopic polypectomy in anticoagulated patients. World journal of gastroenterology: WJG 2009; 15: 1973-1976

[70] Horiuchi A, Nakayama Y, Kajiyama M et al. Removal of small colorectal polyps in anticoagulated patients: a prospective randomized comparison of cold snare and conventional polypectomy. Gastrointestinal endoscopy 2014; 79: 417-423

[71] Takeuchi Y, Mabe K, Shimodate Y et al. Continuous Anticoagulation and Cold Snare Polypectomy Versus Heparin Bridging and Hot Snare Polypectomy in Patients on Anticoagulants With Subcentimeter Polyps: A Randomized Controlled Trial. Annals of internal medicine 2019; 171: 229-237

[72] Hui CK, Lai KC, Yuen MF et al. Does withholding aspirin for one week reduce the risk of post-sphincterotomy bleeding? Alimentary pharmacology \& therapeutics 2002; 16: 929-936

[73] Shiffman ML, Farrel MT, Yee YS. Risk of bleeding after endoscopic biopsy or polypectomy in patients taking aspirin or other NSAIDS. Gastrointestinal endoscopy 1994; 40: 458-462

[74] Yousfi M, Gostout C], Baron TH et al. Postpolypectomy lower gastrointestinal bleeding: potential role of aspirin. The American journal of gastroenterology 2004; 99: 1785-1789

[75] Chan FKL, Kyaw MH, Hsiang JC et al. Risk of Postpolypectomy Bleeding With Uninterrupted Clopidogrel Therapy in an Industry-Independent, Double-Blind, Randomized Trial. Gastroenterology 2019; 156: 918-925 e1

[76] Li DF, Chang X, Fang X et al. Colonoscopic post-polypectomy bleeding in patients on uninterruptedclopidogrel therapy: A systematic review and meta-analysis. Experimental and therapeutic medicine 2020; 19: 3211-3218

[77] Cipolletta L, Rotondano G, Bianco MA et al. Endoscopic resection for superficial colorectal neoplasia in Italy: a prospective multicentre study. Digestive and liver disease : official journal of the Italian Society of Gastroenterology and the Italian Association for the Study of the Liver 2014; 46: 146-151

[78] Heresbach D, Kornhauser R, Seyrig JA et al. A national survey of endoscopic mucosal resection for superficial gastrointestinal neoplasia. Endoscopy 2010; 42: 806-813

[79] Elliott TR, Tsiamoulos ZP, Thomas-Gibson S et al. Factors associated with delayed bleeding after resection of large nonpedunculated colorectal polyps. Endoscopy 2018; 50: 790-799

[80] Qumseya BJ, Wolfsen C, Wang Y et al. Factors associated with increased bleeding post-endoscopic mucosal resection. Journal of digestive diseases 2013; 14: 140-146

[81] Namasivayam V, Prasad GA, Lutzke LS et al. The risk of endoscopic mucosal resection in the setting of clopidogrel use. ISRN gastroenterology 2014; 2014: 494157
[82] Nonaka S, Oda I, Tada K et al. Clinical outcome of endoscopic resection for nonampullary duodenal tumors. Endoscopy 2015; 47: 129135

[83] Liaquat H, Rohn E, Rex DK. Prophylactic clip closure reduced the risk of delayed postpolypectomy hemorrhage: experience in 277 clipped large sessile or flat colorectal lesions and 247 control lesions. Gastrointestinal endoscopy 2013; 77: 401-407

[84] Feagins LA, Nguyen AD, lqbal R et al. The prophylactic placement of hemoclips to prevent delayed post-polypectomy bleeding: an unnecessary practice? A case control study. Digestive diseases and sciences 2014; 59: 823-828

[85] Shioji K, Suzuki Y, Kobayashi M et al. Prophylactic clip application does not decrease delayed bleeding after colonoscopic polypectomy. Gastrointestinal endoscopy 2003; 57: 691-694

[86] Parikh ND, Zanocco K, Keswani RN et al. A cost-efficacy decision analysis of prophylactic clip placement after endoscopic removal of large polyps. Clinical gastroenterology and hepatology : the official clinical practice journal of the American Gastroenterological Association 2013; 11: 1319-1324

[87] Seo M, Song EM, Cho JW et al. A risk-scoring model for the prediction of delayed bleeding after colorectal endoscopic submucosal dissection. Gastrointestinal endoscopy 2019; 89: 990-998 e2

[88] Harada H, Suehiro S, Murakami D et al. Feasibility of gastric endoscopic submucosal dissection with continuous low-dose aspirin for patients receiving dual antiplatelet therapy. World journal of gastroenterology : WJG 2019; 25: 457-468

[89] Horikawa Y, Mizutamari H, Mimori N et al. Effect of Continued Administration of Low-dose Aspirin for Intraoperative Bleeding Contro in Gastric Endoscopic Submucosal Dissection. Digestion 2019; 100: 139-146

[90] Igarashi K, Takizawa K, Kakushima N et al. Should antithrombotic therapy be stopped in patients undergoing gastric endoscopic submucosal dissection? Surgical endoscopy 2017; 31: 1746-1753

[91] Kono Y, Obayashi Y, Baba Y et al. Postoperative bleeding risk after gastric endoscopic submucosal dissection during antithrombotic drug therapy. Journal of gastroenterology and hepatology 2018; 33 : 453-460

[92] Oh S, Kim SG, Kim J et al. Continuous Use of Thienopyridine May Be as Safe as Low-Dose Aspirin in Endoscopic Resection of Gastric Tumors. Gut and liver 2018; 12: 393-401

[93] So S, Ahn JY, Kim N et al. Comparison of the effects of antithrombotic therapy on delayed bleeding after gastric endoscopic resection: a propensity score-matched case-control study. Gastrointestinal endoscopy 2019; 89: 277-285 e2

[94] Dong J, Wei K, Deng J et al. Effects of antithrombotic therapy on bleeding after endoscopic submucosal dissection. Gastrointestinal endoscopy 2017; 86: 807-816

[95] Jaruvongvanich V, Sempokuya T, Wijarnpreecha K et al. Continued versus interrupted aspirin use and bleeding risk after endoscopic submucosal dissection of gastric neoplasms: a meta-analysis. Annals of gastroenterology : quarterly publication of the Hellenic Society of Gastroenterology 2018; 31: 344-349

[96] Tomida H, Yoshio T, Igarashi K et al. Influence of anticoagulants on the risk of delayed bleeding after gastric endoscopic submucosal dissection: a multicenter retrospective study. Gastric cancer : official journal of the International Gastric Cancer Association and the Japanese Gastric Cancer Association 2021; 24: 179-189

[97] Kubo K, Kato M, Mabe K et al. Risk Factors for Delayed Bleeding after Therapeutic Gastrointestinal Endoscopy in Patients Receiving Oral Anticoagulants: A Multicenter Retrospective Study. Digestion 2021; 102: $161-169$

[98] Harada H, Nakahara R, Murakami D et al. The effect of anticoagulants on delayed bleeding after colorectal endoscopic submucosal dissection. Surgical endoscopy 2020; 34: 3330-3337 
[99] Yamashita K, Oka S, Tanaka S et al. Use of anticoagulants increases risk of bleeding after colorectal endoscopic submucosal dissection. Endosc Int Open 2018; 6: E857-E864

[100] Li P, Ma B, Gong S et al. Endoscopic submucosal tunnel dissection for superficial esophageal neoplastic lesions: a meta-analysis. Surgical endoscopy 2020; 34: 1214-1223

[101] Yang D, Zou F, Xiong S et al. Endoscopic submucosal dissection for early Barrett's neoplasia: a meta-analysis. Gastrointestinal endoscopy 2018; 87: 1383-1393

[102] Hanada Y, Wang KK. Safety and feasibility of same-day discharge after esophageal endoscopic submucosal dissection. Gastrointestinal endoscopy 2021; 93: 853-860

[103] Andriulli A, Loperfido S, Napolitano G et al. Incidence rates of postERCP complications: a systematic survey of prospective studies. The American journal of gastroenterology 2007; 102: 1781-1788

[104] Dumonceau JM, Kapral C, Aabakken L et al. ERCP-related adverse events: European Society of Gastrointestinal Endoscopy (ESGE) Guideline. Endoscopy 2020; 52: 127-149

[105] Manes G, Paspatis G, Aabakken L et al. Endoscopic management of common bile duct stones: European Society of Gastrointestinal Endoscopy (ESGE) guideline. Endoscopy 2019; 51: 472-491

[106] Li DF, Yang MF, Chang X et al. Endocut Versus Conventional Blended Electrosurgical Current for Endoscopic Biliary Sphincterotomy: A Meta-Analysis of Complications. Digestive diseases and sciences 2019; 64: 2088-2094

[107] Rey JF, Beilenhoff U, Neumann CS et al. European Society of Gastrointestinal Endoscopy (ESGE) guideline: the use of electrosurgical units. Endoscopy 2010; 42: 764-772

[108] Verma D, Kapadia A, Adler DG. Pure versus mixed electrosurgical current for endoscopic biliary sphincterotomy: a meta-analysis of adverse outcomes. Gastrointestinal endoscopy 2007; 66: 283-290

[109] Abdel Samie AA, Sun R, Vohringer U et al. Safety of endoscopic sphincterotomy in patients under dual antiplatelet therapy. Hepatogastroenterology 2013; 60: 659-661

[110] Koh HR, Park CH, Chung MW et al. Endoscopic retrograde cholangiopancreatography in patients with previous acute coronary syndrome. Gut and liver 2014; 8: 674-679

[111] Lee MG, Kim J, Lee SH et al. Effect of sustained use of platelet aggregation inhibitors on post-endoscopic sphincterotomy bleeding. Digestive endoscopy : official journal of the Japan Gastroenterological Endoscopy Society 2014; 26: 737-744

[112] Onal IK, Parlak E, Akdogan M et al. Do aspirin and non-steroidal antiinflammatory drugs increase the risk of post-sphincterotomy hemorrhage-a case-control study. Clinics and research in hepatology and gastroenterology 2013; 37: 171-176

[113] Nelson DB, Freeman ML. Major hemorrhage from endoscopic sphincterotomy: risk factor analysis. Journal of clinical gastroenterology 1994; 19: 283-287

[114] Rouquette O, Bommelaer G, Abergel A et al. Large balloon dilation post endoscopic sphincterotomy in removal of difficult common bile duct stones: a literature review. World journal of gastroenterology: WJG 2014; 20: 7760-7766

[115] Poincloux L, Rouquette O, Privat J et al. Large-balloon dilation of the sphincter of Oddi after sphincterotomy or infundibulotomy to extract large calculi or multiple common bile duct stones without using mechanical lithotripsy. Scandinavian journal of gastroenterology $2013 ; 48: 246-251$

[116] Spadaccini M, Fugazza A, Frazzoni L et al. Endoscopic papillectomy for neoplastic ampullary lesions: A systematic review with pooled analysis. United European gastroenterology journal 2020; 8: 44-51

[117] Kagawa K, Kubota K, Kurita Y et al. Effect of preventive closure of the frenulum after endoscopic papillectomy: A prospective pilot study. Journal of gastroenterology and hepatology 2020; 35: 374-349
[118] Iwasaki E, Minami K, Itoi T et al. Impact of electrical pulse cut mode during endoscopic papillectomy: Pilot randomized clinical trial. Digestive endoscopy : official journal of the Japan Gastroenterological Endoscopy Society 2020; 32: 127-135

[119] Nam K, Song TJ, Kim RE et al. Usefulness of argon plasma coagulation ablation subsequent to endoscopic snare papillectomy for ampullary adenoma. Digestive endoscopy : official journal of the Japan Gastroenterological Endoscopy Society 2018; 30: 485-492

[120] Yang JK, Hyun J], Lee TH et al. Can prophylactic argon plasma coagulation reduce delayed post-papillectomy bleeding? A prospective multicenter trial. Gastroenterol Hepatol 2021; 36: 467-473

[121] Chung KH, Lee SH, Choi JH et al. Effect of submucosal injection in endoscopic papillectomy of ampullary tumor: Propensity-score matching analysis. United European gastroenterology journal 2018; 6: 576-585

[122] Hyun J], Lee TH, Park JS et al. A prospective multicenter study of submucosal injection to improve endoscopic snare papillectomy for ampullary adenoma. Gastrointestinal endoscopy 2017; 85: 746-755

[123] Wang KX, Ben QW, Jin ZD et al. Assessment of morbidity and mortality associated with EUS-guided FNA: a systematic review. Gastrointestinal endoscopy 2011; 73: 283-290

[124] Li DF, Wang JY, Yang MF et al. Factors associated with diagnostic accuracy, technical success and adverse events of endoscopic ultrasound-guided fine-needle biopsy: A systematic review and metaanalysis. Journal of gastroenterology and hepatology 2020; 35 : 1264-1276

[125] Zhu H, Jiang F, Zhu J et al. Assessment of morbidity and mortality associated with endoscopic ultrasound-guided fine-needle aspiration for pancreatic cystic lesions: A systematic review and metaanalysis. Digestive endoscopy : official journal of the Japan Gastroenterological Endoscopy Society 2017; 29: 667-675

[126] Inoue T, Okumura F, Sano $\mathrm{H}$ et al. Bleeding risk of endoscopic ultrasound-guided fine-needle aspiration in patients undergoing antithrombotic therapy. Digestive endoscopy : official journal of the Japan Gastroenterological Endoscopy Society 2017; 29: 91-96

[127] Kawakubo K, Yane K, Eto K et al. A Prospective Multicenter Study Evaluating Bleeding Risk after Endoscopic Ultrasound-Guided Fine Needle Aspiration in Patients Prescribed Antithrombotic Agents. Gut and liver 2018; 12: 353-359

[128] Kien-Fong VuC, Chang F, Doig L et al. A prospective control study of the safety and cellular yield of EUS-guided FNA or Trucut biopsy in patients taking aspirin, nonsteroidal anti-inflammatory drugs, or prophylactic low molecular weight heparin. Gastrointestinal endoscopy 2006; 63: 808-813

[129] Polmanee P, Hara K, Mizuno N et al. Outcomes of EUS-FNA in patients receiving antithrombotic therapy. Endosc Int Open 2019; 7: E15-E25

[130] Ogura T, Nishioka N, Ueno S et al. Antiplatelet and/or anticoagulant treatment does not increase hemorrhagic adverse events during EUS-guided biliary drainage. Gastrointestinal endoscopy 2020; 92 : 659-666

[131] Harvey PR, Coupland B, Mytton J et al. Outcomes of pneumatic dilatation and Heller's myotomy for achalasia in England between 2005 and 2016. Gut 2019; 68: 1146-1151

[132] Qi L, He W, Yang J et al. Endoscopic balloon dilation and submucosal injection of triamcinolone acetonide in the treatment of esophageal stricture: A single-center retrospective study. Exp Ther Med 2018; 16: 5248-5252

[133] Vermeulen BD, de Zwart M, Sijben J et al. Risk factors and clinica outcomes of endoscopic dilation in benign esophageal strictures: a long-term follow-up study. Gastrointestinal endoscopy 2020; 91: 1058-1066 
[134] Pope E, Mansour M, Berseneva M et al. Outcomes and Predictors for Re-stenosis of Esophageal Stricture in Epidermolysis Bullosa: A Multicenter Cohort Study. J Pediatr Gastroenterol Nutr 2020; 71: 310314

[135] Dougherty M, Runge TM, Eluri S et al. Esophageal dilation with either bougie or balloon technique as a treatment for eosinophilic esophagitis: a systematic review and meta-analysis. Gastrointest Endosc 2017; 86: 581-591 e3

[136] Runge TM, Eluri S, Cotton CC et al. Outcomes of Esophageal Dilation in Eosinophilic Esophagitis: Safety, Efficacy, and Persistence of the Fibrostenotic Phenotype. Am J Gastroenterol 2016; 111: 206-213

[137] Kochhar R, Malik S, Gupta P et al. Etiological spectrum and response to endoscopic balloon dilation in patients with benign gastric outlet obstruction. Gastrointest Endosc 2018; 88: 899-908

[138] Baumann AJ, Mramba LK, Hawkins RB et al. Endoscopic Dilation of Bariatric RNY Anastomotic Strictures: a Systematic Review and Metaanalysis. Obes Surg 2018; 28: 4053-4063

[139] Kishida Y, Kakushima N, Kawata N et al. Complications of endoscopic dilation for esophageal stenosis after endoscopic submucosal dissection of superficial esophageal cancer. Surg Endosc 2014; 29: 2953-2959

[140] van Halsema EE, Noordzij IC, van Berge Henegouwen MI et al. Endoscopic dilation of benign esophageal anastomotic strictures over 16 mm has a longer lasting effect. Surg Endosc 2017; 31: 18711881

[141] Bettenworth D, Gustavsson A, Atreja A et al. A Pooled Analysis of Efficacy, Safety, and Long-term Outcome of Endoscopic Balloon Dilation Therapy for Patients with Stricturing Crohn's Disease. Inflamm Bowel Dis 2017; 23: 133-142

[142] Molina JC, Goudie E, Pollock C et al. Balloon Dilation for Endosonographic Staging in Esophageal Cancer - A Phase 1 Clinical Trial. Ann Thorac Surg 2020; 28: 28

[143] Lan N, Wu JJ, Wu XR et al. Endoscopic treatment of pouch inlet and afferent limb strictures: stricturotomy vs. balloon dilation. Surg Endosc 2020; 35: 1722-1733

[144] Andujar X, Loras C, Gonzalez B et al. Efficacy and safety of endoscopic balloon dilation in inflammatory bowel disease: results of the large multicenter study of the ENEIDA registry. Surgical Endoscopy 2020; 34: 1112-1122

[145] Lan N, Shen B. Endoscopic Stricturotomy Versus Balloon Dilation in the Treatment of Anastomotic Strictures in Crohn's Disease. Inflamm Bowel Dis 2018; 24: 897-907

[146] Lan N, Stocchi L, Ashburn JH et al. Outcomes of Endoscopic Balloon Dilation vs Surgical Resection for Primary lleocolic Strictures in Patients With Crohn's Disease. Clin Gastroenterol Hepatol 2018; 16: 1260-1267

[147] Biraima M, Adamina M, Jost R et al. Long-term results of endoscopic balloon dilation for treatment of colorectal anastomotic stenosis. Surg Endosc 2016; 30: 4432-4437

[148] Metman EH, Lagasse JP, d'Alteroche L et al. Risk factors for immediate complications after progressive pneumatic dilation for achalasia. The American journal of gastroenterology 1999; 94: 1179-1185

[149] Boeckxstaens GE, Annese V, des Varannes SB et al. Pneumatic dilation versus laparoscopic Heller's myotomy for idiopathic achalasia. The New England journal of medicine 2011; 364: 1807-1816

[150] Didden P, Reijm AN, Erler NS et al. Fully vs. partially covered selfexpandable metal stent for palliation of malignant esophageal strictures: a randomized trial (the COPAC study). Endoscopy 2018; 50: 961-971

[151] Kim JY, Kim SG, Lim JH et al. Clinical outcomes of esophageal stents in patients with malignant esophageal obstruction according to palliative additional treatment. J Dig Dis 2015; 16: 575-584
[152] Mao-de-Ferro S, Serrano M, Ferreira S et al. Stents in patients with esophageal cancer before chemoradiotherapy: high risk of complications and no impact on the nutritional status. European Journal of Clinical Nutrition 2016; 70: 409-410

[153] Padhan RK, Nongthombam SK, Venuthurimilli A et al. Assessment of safety and efficacy of an indigenous self-expandable fully covered esophageal metal stent for palliation of esophageal cancer. Indian J Cancer 2016; 53: 534-537

[154] So H, Ahn JY, Han S et al. Efficacy and Safety of Fully Covered SelfExpanding Metal Stents for Malignant Esophageal Obstruction. Dig Dis Sci 2018; 63: 234-241

[155] Vermeulen BD, Reijm AN, van der Bogt RD et al. Through-the-scope placement of a fully covered metal stent for palliation of malignant dysphagia: a prospective cohort study (with video). Gastrointest Endosc 2019; 90: 972-979

[156] Bechtler M, Wagner F, Fuchs ES et al. Biliary metal stents for proximal esophageal or hypopharyngeal strictures. Surg Endosc 2015; 29: 3205-3208

[157] McCain S, McCain S, Quinn B et al. The role of biodegradable stents in the management of benign and malignant oesophageal strictures: A cohort study. Surgeon 2016; 14: 322-326

[158] White RE, Chepkwony R, Mwachiro M et al. Randomized Trial of Small-diameter Versus Large-diameter Esophageal Stents for Palliation of Malignant Esophageal Obstruction. J Clin Gastroenterol 2015; 49: 660-665

[159] Reijm AN, Didden P, Schelling SJC et al. Self-expandable metal stent placement for malignant esophageal strictures - changes in clinical outcomes over time. Endoscopy 2019; 51: 18-29

[160] Iwasaki H, Mizushima T, Suzuki Y et al. Factors That Affect StentRelated Complications in Patients with Malignant Obstruction of the Esophagus or Gastric Cardia. Gut Liver 2017; 11: 47-54

[161] Choi YK, Ahn JY, Na HK et al. Winged Partially Covered Self-Expandable Metal Stent to Prevent Distal Migration in Malignant Gastric Outlet Obstruction. Dig Dis Sci 2018; 63: 3409-3416

[162] Kumar V, Ghoshal UC, Mohindra S et al. Palliation of malignant gastroduodenal obstruction with self-expandable metal stent using side- and forward-viewing endoscope: Feasibility and outcome. Jgh Open 2019; 3: 65-70

[163] Lee H, Min BH, Lee JH et al. Covered metallic stents with an anti-migration design vs. uncovered stents for the palliation of malignant gastric outlet obstruction: a multicenter, randomized trial. Am J Gastroenterol 2015; 110: 1440-1449

[164] Miyabe K, Hayashi K, Nakazawa T et al. Safety and benefits of selfexpandable metallic stents with chemotherapy for malignant gastric outlet obstruction. Dig Endosc 2015; 27: 572-581

[165] Bayraktar B, Ozemir IA, Kefeli U et al. Colorectal stenting for palliation and as a bridge to surgery: A 5-year follow-up study. World J Gastroenterol 2015; 21: 9373-9379

[166] Consolo P, Giacobbe G, Cintolo M et al. Colonic acute malignant obstructions: effectiveness of self-expanding metallic stent as bridge to surgery. Turkish Journal of Gastroenterology 2017; 28: 40-45

[167] Feng YD, Yu Q, Li M et al. Endoscopic Self-Expandable Metallic Stent Insertion without Fluoroscopic Guidance Is Feasible and Safe for Acute Colonic Obstruction Caused by Colorectal Cancer. Gastroenterol Res Pract 2020: doi:10.1155/2020/6810164 [Published online 10 Jan 2020]

[168] Gurbulak B, Gurbulak EK, Akgun IE et al. Endoscopic stent placement in the management of malignant colonic obstruction: Experiences from two centers. Ulus Cerrahi Derg 2015; 31: 132-137

[169] Cheng Y, Zhu Y. 03: 54 PM Abstract No. 312 Comparison of throughthe-scope stent insertion with standard stent insertion for the management of malignant colorectal obstruction: a prospective study. Journal of vascular and interventional radiology 2019; 30: S138-S9 
[170] Han L], Song X], Yu B et al. Safety evaluation of preoperative stent insertion and clinical analysis on comparison of outcomes between preoperative stent insertion and emergency surgery in the treatment of obstructive left-sided colorectal cancer. Pakistan Journal of Medical Sciences 2020; 36: 376-381

[171] Parodi A, De Ceglie A, De Luca L et al. Endoscopic stenting as bridgeto-surgery (BTS) in left-sided obstructing colorectal cancer: Experience with conformable stents. Clinics and Research in Hepatology and Gastroenterology 2016; 40: 638-644

[172] Saeed KM, Zafar W, Masood MA et al. Self-Expanding Metallic Stents (SEMS) in Left-Sided Colonic Cancer-a Cancer Center Experience. J Gastrointest Cancer 2016; 47: 69-74

[173] Faraz S, Salem SB, Schattner M et al. Predictors of clinical outcome of colonic stents in patients with malignant large-bowel obstruction because of extracolonic malignancy. Gastrointestinal Endoscopy 2018; 87: 1310-1317

[174] Miyasako Y, Kuwai T, Ishaq S et al. Newly developed self-expandable Niti-S MD colonic metal stent for malignant colonic obstruction. World J Gastrointest Surg 2020; 12: 138-148

[175] Atukorale YN, Church JL, Hoggan BL et al. Self-Expanding Metallic Stents for the Management of Emergency Malignant Large Bowel Obstruction: a Systematic Review. J Gastrointest Surg 2016; 20: 455-462

[176] Rahnemai-Azar AA, Rahnemaiazar AA, Naghshizadian R et al. Percutaneous endoscopic gastrostomy: indications, technique, complications and management. World journal of gastroenterology: WJG 2014; 20: 7739-7751

[177] Schurink CA, Tuynman H, Scholten P et al. Percutaneous endoscopic gastrostomy: complications and suggestions to avoid them. European journal of gastroenterology \& hepatology 2001; 13: 819-823

[178] Ubogu EE, Zaidat OO. Rectus sheath hematoma complicating percutaneous endoscopic gastrostomy. Surgical laparoscopy, endoscopy \& percutaneous techniques 2002; 12: 430-432

[179] Anderloni A, Di Leo M, Barzaghi F et al. Complications and early mortality in percutaneous endoscopic gastrostomy placement in lombardy: A multicenter prospective cohort study. Digestive and liver disease: official journal of the Italian Society of Gastroenterology and the Italian Association for the Study of the Liver 2019; 51: $1380-1387$

[180] Lucendo A], Sanchez-Casanueva T, Redondo O et al. Risk of bleeding in patients undergoing percutaneous endoscopic gastrotrostomy (PEG) tube insertion under antiplatelet therapy: a systematic review with a meta-analysis. Revista espanola de enfermedades digestivas : organo oficial de la Sociedad Espanola de Patologia Digestiva 2015; 107: $128-136$

[181] Richter-Schrag H], Richter S, Ruthmann O et al. Risk factors and complications following percutaneous endoscopic gastrostomy: a case series of 1041 patients. Canadian journal of gastroenterology = Journal canadien de gastroenterologie 2011; 25: 201-206

[182] Richter JA, Patrie JT, Richter RP et al. Bleeding after percutaneous endoscopic gastrostomy is linked to serotonin reuptake inhibitors, not aspirin or clopidogrel. Gastrointestinal endoscopy 2011; 74: 2234 e1

[183] Gerson LB, Tokar J, Chiorean M et al. Complications associated with double balloon enteroscopy at nine US centers. Clinical gastroenterology and hepatology : the official clinical practice journal of the American Gastroenterological Association 2009; 7: 1177-1182, 82 e1-3

[184] Noujaim MG, Parish A, Raines D et al. Use, Yield, and Risk of Deviceassisted Enteroscopy in the United States: Results From a Large Retrospective Multicenter Cohort. J Clin Gastroenterol 2020: doi:10.1097/MCG.0000000000001426 [Epub ahead of print: 17 Sep 2020]
[185] Buscaglia JM, Dunbar KB, Okolo PI et al. The spiral enteroscopy training initiative: results of a prospective study evaluating the Discovery SB overtube device during small bowel enteroscopy (with video). Endoscopy 2009; 41: 194-199

[186] Moschler O, May A, Muller MK et al. Complications in and performance of double-balloon enteroscopy (DBE): results from a large prospective DBE database in Germany. Endoscopy 2011; 43: 484-489

[187] Shelnut DJ, Sims OT, Zaibaq JN et al. Predictors for outcomes and readmission rates following double balloon enteroscopy: a tertiary care experience. Endosc Int Open 2018; 6: E751-E757

[188] Pattni V, Tate DJ, Terlevich A et al. Device-assisted enteroscopy in the UK: description of a large tertiary case series under conscious sedation. Frontline gastroenterology 2018; 9: 122-128

[189] Vanbiervliet G, Giudicelli-Bornard S, Piche T et al. Predictive factors of bleeding related to post-banding ulcer following endoscopic variceal ligation in cirrhotic patients: a case-control study. Alimentary pharmacology \& therapeutics 2010; 32: 225-232

[190] Bianchini M, Cavani G, Bonaccorso A et al. Low molecular weight heparin does not increase bleeding and mortality post-endoscopic variceal band ligation in cirrhotic patients. Liver international: official journal of the International Association for the Study of the Liver 2018; 38: 1253-1262

[191] Bajaj JS, Franco J. Endoscopic band ligation of esophageal varices in patients on anticoagulation. Journal of clinical gastroenterology 2008; 42: 782-785

[192] Duenas E, Cachero A, Amador A et al. Ulcer bleeding after band ligation of esophageal varices: Risk factors and prognosis. Digestive and liver disease : official journal of the Italian Society of Gastroenterology and the Italian Association for the Study of the Liver 2020; 52: 79-83

[193] Qumseya B], Wani S, Desai M et al. Adverse Events After Radiofrequency Ablation in Patients With Barrett's Esophagus: A Systematic Review and Meta-analysis. Clinical gastroenterology and hepatology : the official clinical practice journal of the American Gastroenterological Association 2016; 14: 1086-1095 e6

[194] Maida M, Camilleri S, Manganaro M et al. Radiofrequency Ablation for Treatment of Refractory Gastric Antral Vascular Ectasia: A Systematic Review of the Literature. Gastroenterology research and practice 2017; 2017: 5609647

[195] Eisenberg MJ, Richard PR, Libersan D et al. Safety of short-term discontinuation of antiplatelet therapy in patients with drug-eluting stents. Circulation 2009; 119: 1634-1642

[196] Scott M], Veitch A, Thachil J. Reintroduction of anti-thrombotic therapy after a gastrointestinal haemorrhage: if and when? British journal of haematology 2017; 177: 185-197

[197] Sung JJ, Lau JY, Ching JY et al. Continuation of low-dose aspirin therapy in peptic ulcer bleeding: a randomized trial. Annals of internal medicine 2010; 152: 1-9

[198] Siau K, Hannah JL, Hodson J et al. Stopping antithrombotic therapy after acute upper gastrointestinal bleeding is associated with reduced survival. Postgraduate medical journal 2018; 94: 137-142

[199] Hearnshaw SA, Logan RF, Lowe D et al. Acute upper gastrointestinal bleeding in the UK: patient characteristics, diagnoses and outcomes in the 2007 UK audit. Gut 2011; 60: 1327-1335

[200] Marmo R, Koch M, Cipolletta L et al. Predicting mortality in nonvariceal upper gastrointestinal bleeders: validation of the Italian PNED Score and Prospective Comparison with the Rockall Score. The American journal of gastroenterology 2010; 105: 1284-1291

[201] Oakland K, Guy R, Uberoi R et al. Acute lower GI bleeding in the UK: patient characteristics, interventions and outcomes in the first nationwide audit. Gut 2018; 67: 654-662

[202] Oakland K, Kothiwale S, Forehand T et al. External Validation of the Oakland Score to Assess Safe Hospital Discharge Among Adult Pa- 
tients With Acute Lower Gastrointestinal Bleeding in the US. JAMA Netw Open 2020; 3: e209630

[203] Rubin TA, Murdoch M, Nelson DB. Acute Gl bleeding in the setting of supratherapeutic international normalized ratio in patients taking warfarin: endoscopic diagnosis, clinical management, and outcomes. Gastrointestinal endoscopy 2003; 58: 369-373

[204] Shingina A, Barkun AN, Razzaghi A et al. Systematic review: the presenting international normalised ratio (INR) as a predictor of outcome in patients with upper nonvariceal gastrointestinal bleeding. Alimentary pharmacology \& therapeutics 2011; 33: 1010-1018

[205] Strate LL, Orav EJ, Syngal S. Early predictors of severity in acute lower intestinal tract bleeding. Archives of internal medicine 2003; 163: 838-843

[206] Ansell ], Hirsh J, Hylek E et al. Pharmacology and management of the vitamin K antagonists: American College of Chest Physicians Evidence-Based Clinical Practice Guidelines (8th Edition). Chest 2008; 133: 160S-198S

[207] Radaelli F, Dentali F, Repici A et al. Management of anticoagulation in patients with acute gastrointestinal bleeding. Digestive and liver disease : official journal of the Italian Society of Gastroenterology and the Italian Association for the Study of the Liver 2015; 47: 621627

[208] Nagata N, Sakurai T, Moriyasu S et al. Impact of INR monitoring, reversal agent use, heparin bridging, and anticoagulant interruption on rebleeding and thromboembolism in acute gastrointestinal bleeding. PloS one 2017; 12: e0183423

[209] Steffel ], Verhamme P, Potpara TS et al. The 2018 European Heart Rhythm Association Practical Guide on the use of non-vitamin K antagonist oral anticoagulants in patients with atrial fibrillation. European heart journal 2018; 39: 1330-1393

[210] Tomaselli GF, Mahaffey KW, Cuker A et al. 2020 ACC Expert Consensus Decision Pathway on Management of Bleeding in Patients on Oral Anticoagulants: A Report of the American College of Cardiology Solution Set Oversight Committee. Journal of the American College of Cardiology 2020; 76: 594-622

[211] Cuker A, Burnett A, Triller D et al. Reversal of direct oral anticoagulants: Guidance from the Anticoagulation Forum. American journal of hematology 2019; 94: 697-709

[212] Pollack CV Jr, Reilly PA, van Ryn J et al. Idarucizumab for Dabigatran Reversal - Full Cohort Analysis. The New England journal of medicine 2017; 377: 431-441

[213] Connolly S], Crowther M, Eikelboom JW et al. Full Study Report of Andexanet Alfa for Bleeding Associated with Factor Xa Inhibitors. The New England journal of medicine 2019; 380: 1326-1335
[214] Majeed A, Agren A, Holmstrom M et al. Management of rivaroxabanor apixaban-associated major bleeding with prothrombin complex concentrates: a cohort study. Blood 2017; 130: 1706-1712

[215] Piran S, Khatib R, Schulman S et al. Management of direct factor Xa inhibitor-related major bleeding with prothrombin complex concentrate: a meta-analysis. Blood Adv 2019; 3: 158-167

[216] Smith MN, Deloney L, Carter C et al. Safety, efficacy, and cost of four-factor prothrombin complex concentrate (4F-PCC) in patients with factor $X$ a inhibitor-related bleeding: a retrospective study. Journal of thrombosis and thrombolysis 2019; 48: 250-255

[217] Choudari CP, Rajgopal C, Palmer KR. Acute gastrointestinal haemorrhage in anticoagulated patients: diagnoses and response to endoscopic treatment. Gut 1994; 35: 464-466

[218] Jamula E, Lloyd NS, Schwalm JD et al. Safety of uninterrupted anticoagulation in patients requiring elective coronary angiography with or without percutaneous coronary intervention: a systematic review and metaanalysis. Chest 2010; 138: 840-847

[219] Qureshi W, Mittal C, Patsias I et al. Restarting anticoagulation and outcomes after major gastrointestinal bleeding in atrial fibrillation. The American journal of cardiology 2014; 113: 662-668

[220] Sengupta N, Feuerstein JD, Patwardhan VR et al. The risks of thromboembolism vs. recurrent gastrointestinal bleeding after interruption of systemic anticoagulation in hospitalized inpatients with gastrointestinal bleeding: a prospective study. . The American journal of gastroenterology 2015; 110: 328-335

[221] Staerk L, Lip GY, Olesen JB et al. Stroke and recurrent haemorrhage associated with antithrombotic treatment after gastrointestinal bleeding in patients with atrial fibrillation: nationwide cohort study. Bmj 2015; 351: h5876

[222] Witt DM, Delate T, Garcia DA et al. Risk of thromboembolism, recurrent hemorrhage, and death after warfarin therapy interruption for gastrointestinal tract bleeding. Archives of internal medicine 2012; 172: 1484-1491

[223] Little D, Chai-Adisaksopha C, Hillis C et al. Resumption of anticoagulant therapy after anticoagulant-related gastrointestinal bleeding: A systematic review and meta-analysis. Thrombosis research 2019; 175: 102-109

[224] Tapaskar N, Pang A, Werner DA et al. Resuming Anticoagulation Following Hospitalization for Gastrointestinal Bleeding Is Associated with Reduced Thromboembolic Events and Improved Mortality: Results from a Systematic Review and Meta-Analysis. Digestive diseases and sciences 2021; 66: 554-566 